\title{
A Time-Varying "Natural" Rate of Interest for the Euro Area
}

\author{
J.-S. Mésonnier, J.-P. Renne* \\ Banque de France
}

August 6, 2004

\begin{abstract}
In this article we estimate a time-varying "natural" rate of interest (TVNRI) for a synthetic euro area over the period 1979Q1-2002Q4 using a small backward-looking macroeconomic model, broadly following a methodology developed by Laubach and Williams (2003) for the United States. The Kalman filter simultaneously estimates two unobservable variables: the output gap and the natural rate of interest. The underlying state-space model incorporates an aggregate demand equation and a Phillips curve. Consistent with the theoretical intuition, our identifying assumptions include a close relationship between the TVNRI and the low-frequency fluctuations of potential output growth. The resulting interest rate gap, that is, the difference between the real rate of interest and its estimated natural level, provides us with a valuable tool for assessing the monetary policy stance in EU12 over the last two decades. While our TVNRI estimate seems quite robust to changes in model specifications, the relatively high uncertainty surrounding the estimate hampers its direct integration into the policy-making process.
\end{abstract}

\footnotetext{
*Banque de France, Monetary Policy Research Unit, 41-1422 SEPMF, 75049 Paris cedex 01. Corresponding author: J.S. Mésonnier, e-mail: jean-stephane.mesonnier@banque-france.fr. We are grateful to Gilbert Cette, Laurent Clerc, Patrick Fève, Enisse Kharroubi, Hervé Le Bihan, Julien Matheron, Adrien Verdelhan and participants in an internal Banque de France seminar for useful comments and suggestions. All errors remain our own. Opinions expressed reflect the authors'view only and not necessarily the position of the Banque de France.
} 


\section{Introduction}

In this paper, we estimate a time-varying "natural" rate of interest (TVNRI) for the euro area within the framework of a small backward-looking macroeconomic model and using the Kalman filter along the lines of Laubach and Williams (2003).

The concept of a "natural" real rate of interest and its prescriptive use for monetary policy is generally associated with the Swedish pre-keynesian economist Knut Wicksell $(1898,1906,1907)$. According to this early contribution, "there is a certain rate of interest on loans which is neutral in respect to commodity prices and tends neither to raise nor to lower them" (1936, p. 102). In Wicksell's view, price stability hence depends on keeping the (real) interest rate of credit -understood to be equal to the discount rate controlled by the central bank- in line with the neutral rate of interest, which varies according to shocks affecting its (real) determinants, mainly the productivity of capital.

Although one may consider that a "natural" rate of interest (NRI) appears implicitly as the intercept in popular interest rate rules of the kind first proposed by Taylor (1993) roughly a decade ago, the recent revival of the concept owes much to the "Neo-wicksellian" framework for monetary policy analysis advocated by Woodford (2003), where the neutral rate embedded in the Taylor rule varies continuously in response to various real disturbances. The interest rate gap, then defined as the difference between the real short term interest rate representative of monetary policy and its equilibrium or "natural" counterpart, seems to be an interesting candidate for assessing the current monetary policy stance, notably as an alternative to measures that employ monetary aggregates or exchange rates. Hence, central banks and central bank economists have recently devoted much attention to these theoretical developments and the resulting empirical estimation strategies (see, e.g., ECB, 2004, Christensen, 2002, Williams, 2003, Crespo-Cuaresma et al., 2003, Basdevant et al., 2004).

A more careful reading of this expanding literature however reveals two main approaches, depending on whether the focus is on short term or medium to long run implications of a non-zero gap and, simultaneously, on the degree of structure put into the models that yield the estimates.

A first strand of this new "natural" rate literature broadly follows the lines of Blinder (1998), Woodford (2003) or Neiss and Nelson (2001) and derives the natural rate of interest within the framework of detailed structural "New Keynesian" models (see, e.g., Giammarioli and Valla, 2003, Smets and Wouters, 2002, for applications to the euro area). From this perspective, the natural rate of interest equals the equilibrium real rate of return in an economy where prices are fully flexible, or in other words, it is the real short term rate of interest that equates aggregate demand with potential output at all times. The emphasis is thus put on short term developments. Neiss and Nelson (2001) for instance develop a dynamic stochastic general equilibrium (DSGE) model with sticky prices that they calibrate to the UK economy: they then compute what Laubach and Williams (2003) term the "higher frequency component" of the natural rate of interest and track the period-by-period movements in the 
real rate of interest that are required to keep inflation constant. As Larsen and McKeown (2002) state it, such a DSGE approach is a priori desirable, because it obviously enables a structural interpretation of the interest rate gap and its variations, which pure statistical approaches (such as a band pass or a HP filter) do not allow. However, as far as its prescriptive use for policy purposes is concerned, the advantage of such an approach over more statistical ones is not clear-cut, at least given that the calibration exercise of the derived models usually implies a significant amount of arbitrary assumptions. Besides, the natural rate of interest generated by a DSGE model appears in some cases to be substantially more volatile than the actual real rate, which makes policy use quite difficult (see, e.g., results in Smets and Wouters, 2002). Be that as it may, Neiss and Nelson (2001) for the UK as well as Giammarioli and Valla (2003) for the euro area provide promising results suggesting that their interest rate gap estimates have an informational content for inflation that could be used for policy purpose.

Another strand of the literature follows Laubach and Williams (2003) and mixes the reference to simple macroeconomic models usually found in the monetary policy literature with the use of semi-structural methods such as the Kalman filter in order to estimate the natural rate of interest, the potential level of output and/or the natural rate of unemployment as unobserved variables (recent examples include Orphanides and Williams, 2002, Crespo-Cuaresma et al., 2003, Basdevant et al., 2004). In this view, the natural rate of interest is the real short term rate of interest consistent with output at its potential and inflation equal to its target in the medium run, i.e. once the effects of demand shocks on the output gap and supply shocks on inflation have completely vanished. Though it is less precise than the former, this latter definition seems to be more tractable in practice and hence more widely accepted.

In a very stimulating contribution, Orphanides and Williams (2002) warn against the adverse and often undervalued consequences of misperceptions in the true NRI -and of its companion concepts of natural rate of unemployment and potential output- in terms of the stabilisation properties of monetary policy rules that include such unobserved variables. They compute various statistical estimates of the "natural" rate including the output of simple state-space models of the kind introduced by Laubach and Williams and compare the properties of policies optimised so as to provide a good stabilisation performance of inflation and output, but which possibly underestimate the magnitude of mismeasurements in the natural rate of interest. They conclude that the costs associated with underestimating natural rate mismeasurement are significantly higher than those of overestimating it. It follows that, given the uncertainty, central bankers need to be extremely cautious regarding the policy implications of the interest rate gaps they compute. This lesson converges with the conclusion of Laubach and Williams, who point out the high uncertainty surrounding estimates of "natural" rates in general.

Along with Larsen and McKeown (2002) however, we argue that there is a case for the use of natural rate estimates obtained via semi-structural techniques such as those employed by Laubach and Williams, which strike a convenient 
compromise between the DSGE approach and purely statistical estimates such as the commonly used HP filter. When not used as a basis for real-time prescription nor as a firm anchor for monetary policy (as advocated e.g. by Christensen, 2002), such estimates of the "natural" rate and of the interest rate gap provide a useful tool for an ex post assessment of the policy stance. Moreover, and, by essence, since they allow for large changes in structural variables like the level of potential output and the NRI, they can deal with and reasonably account for the large shocks and many structural changes that have affected European economies over the last two to three decades. Low-frequency movements of such variables remain a priori out of reach of a more structural approach like DSGE models, where aggregate relationships are expressed as log-linear approximations around a non stochastic steady state.

We apply the methodology first developed by Laubach and Williams (2003) to a synthetic euro area over the period 1979Q1-2002Q4. However, our model specifications depart from theirs in three significant ways. Firstly, we assume that the unobservable process that drives, as in Laubach and Williams, the low frequency common fluctuations of both the NRI and potential output growth remains stationary autoregressive instead of nonstationary, although we expect it to be persistent ${ }^{1}$. This allows us to avoid the difficult reconciliation of a nonstationary output growth and a nonstationary equilibrium real interest rate with both economic theory and intuition. Secondly, as we express some doubt regarding the feasability of estimating our already unobservable NRI as the sum of two equally unobservable components, we opt for a specification of the NRI whose degree of sophistication can be viewed as a compromise between those of Laubach and Williams and Orphanides and Williams, who do not assume any co-movements between the NRI and potential ouput growth. Lastly, we compute the real interest rate as a model-consistent ex ante real rate of interest, using the inflation expectations provided by the model instead of deriving them from univariate autoregressive models of inflation as Laubach and Williams and others do.

The maximum likelihood estimation involves the calibration of two ratios in order to overcome the so-called pile-up problem, and the choice of the calibrated ratios relies on several statistical criteria. Our TVNRI nevertheless appears to be robust to changes in both ratios. The estimated NRI and the derived interest rate gap -the difference between the real short term interest rate and the natural rate-constitute valuable tools for assessing the monetary policy stance in EU12 over the last two decades. In particular, the superiority of such estimates in comparison with classical univariate filters is illustrated. However, the confi-

\footnotetext{
${ }^{1}$ The specification of a nonstationary process for the natural rate of interest and/or the rate of growth of potential output is relatively common in the literature : see e.g. Laubach and Williams (2003), Orphanides and Williams (2002), Larsen and McKeown (2002), Fabiani and Mestre (2001) or Crespo Cuaresma and Gnan (2003). The random walk assumption for the natural rate of interest has the technical advantage of combining persistent changes in the unobservable component with a smooth accomodation of plausible but unspecified structural breaks in the effective interest rate series over a period of estimation that generally covers the last two to three decades. Nevertheless, using a unobservable components setting for the euro area, Gerlach and Smets (1999) assume that potential output is I(1).
} 
dence interval, integrating the uncertainty associated with Kalman filtering, remains relatively broad. Besides, the real-time misperception of the natural rate of interest (that can be approximated by the difference between the two-sided estimates -using the whole sample information- and the one-sided estimates -using only information up to time $t$ ) can also be substantial ${ }^{2}$.

The rest of the paper is organised as follows. Section 2 presents the data set. Section 3 introduces the model. Section 4 develops estimation issues. Lastly, Section 5 analyses the results and examines our estimated TVNRI.

\section{Data}

The euro area time series are taken from ECB's AWM database and cover the period 1979Q1-2002Q4 with quarterly frequency (see Fagan et al., 2000). The first year corresponds to the EMS entering into force. Whereas the real GDP figures provided by the AWM database are already seasonally adjusted, the HICP series is not and we hence adjust it using the Tramo/Seats ${ }^{3}$ procedure.

We denote by $y_{t}$ the log real GDP. Inflation is defined as the annualised quarterly growth rate of the HICP series (in logs) and is denoted by $\pi_{t}$. The ex ante real short term rate of interest $r_{t}$ is obtained by deducting from the current level of the 3 -month nominal rate of interest $i_{t}$ the one-quarter-ahead expectation of (quarterly annualised) inflation as derived from the entire model estimation (denoted with $\pi_{t+1 \mid t}$ below). A novelty of our approach is hence to compute an ex ante real rate of interest using model-consistent inflation expectations instead of proxies for expectations as derived from univariate models of price dynamics or other external modelisation of inflation. Appendix 2 provides with an assessment of the quality of our model-consistent inflation expectations and compares them with alternative inflation expectations derived from both continuously updated univariate autoregressive models of inflation and the univariate time-varying coefficients procedure described by Stock and Watson (1996). Figure 12 plots our model-consistent inflation expectations together with the one-quarter-lead of quarterly annualised inflation.

To end with, two variables are unobservable and constitute the state variables in the state-space model described in the following section, namely the output gap $z_{t}$ and the natural rate of interest $r_{t}^{*}$.

\section{Specifications}

Our specifications are close to these of Laubach and Williams (2003), themselves partly following the lines of Rudebusch and Svensson (1998). The model

\footnotetext{
${ }^{2}$ Note that this measure of misperception is potentially optimistic since even in the onesided case, the whole sample information has been used to estimate the model parameters and is consequently not exactly a "real-time" estimate of the NRI.

${ }^{3}$ The automatically selected specifications for the HICP series is $(2,2,0)(0,1,1)$ in the BoxJenkins notation. These specifications are consistent with our assumption of an $I(1)$ process for $\pi_{t}$.
}

- insert Figure

12 here - 
relies on six backward-looking linear equations. This backward-looking nature of the model makes it subject to the Lucas critique, according to which reducedform relations in traditional macroeconomic models depend implicitly on the agents'expectations of the policy process and are hence unlikely to remain stable as policymakers changed their rules. However, empirical backward-looking models without explicit expectations are still widely used for monetary policy analysis, as in Rudebusch and Svensson (1998, 2002), Onatski and Stock (2002), Smets (1998), Dennis (2001), Laubach and Williams (2003), Fagan, Henry and Mestre (2001) and Fabiani and Mestre (2004). Moreover, several articles suggest that such models appear to be fairly robust empirically, notably Rudebusch and Svensson (1998), Bernanke and Mihov (1998), Estrella and Fuhrer (1999), Dennis (2001) and Leeper and Zha (2002). The model consists of the following equations:

$$
\begin{aligned}
\pi_{t+1} & =A(L) \pi_{t}+B(L) z_{t}+\varepsilon_{t+1}^{\pi} \\
z_{t+1} & =\Phi(L) z_{t}+\Lambda(L)\left(i_{t}-\pi_{t+1 \mid t}-r_{t}^{*}\right)+\varepsilon_{t+1}^{z} \\
r_{t}^{*} & =\mu_{r}+\theta_{r} a_{t} \\
\Delta y_{t}^{*} & =\mu_{y}+\theta_{y} a_{t}+\varepsilon_{t}^{y} \\
a_{t+1} & =\psi a_{t}+\varepsilon_{t+1}^{a} \\
y_{t} & =y_{t}^{*}+z_{t}
\end{aligned}
$$

where $L$ denotes the lag operator. We assume that the four shocks are independently normally distributed, their variance covariance matrix $\Sigma_{\varepsilon}$ is given by:

$$
\Sigma_{\varepsilon}=\left[\begin{array}{cccc}
\sigma_{\pi}^{2} & 0 & \cdots & 0 \\
0 & \sigma_{z}^{2} & \ddots & \vdots \\
\vdots & \ddots & \sigma_{y}^{2} & 0 \\
0 & \cdots & 0 & \sigma_{a}^{2}
\end{array}\right], \sigma_{a}^{2}=1
$$

The first equation can be interpreted as an aggregate supply equation, or "Phillips curve". It relates consumer price inflation to its own lags and to the lagged output gap. The second one is a reduced form of an aggregate demand equation, or "IS curve", relating the output gap to its own lags and to the interest rate gap -i.e. the difference between the short term real rate and the natural rate of interest. Policymakers then control the inflation rate with a lag of two periods. The natural rate of interest is identified through the interest rate gap. More precisely, the output gap is assumed to converge to zero in the absence of demand shocks and if the real rate gap closes. In this model, stable inflation is consistent with both null output and interest rate gaps. Hence, our NRI could also be conveniently labelled as a "nonaccelerating-inflation rate of interest" (NAIRI). An important feature of the model is the fact that monetary policy only affects the rate of inflation indirectly, via the output gap. Lastly, 
we take the nominal short rate of interest as exogenous, or, put differently, the reaction function of the central bank remains implicit.

Departing from common specifications in the literature ${ }^{4}$, we assume that the natural rate of interest $r_{t}^{*}$ follows an autoregressive process instead of a random walk, as specified by (3) and (5). The complete estimation of the model confirms that this process is in fact highly persistent (see the estimator of $\psi$ in Table 1), which fits our purpose of capturing large and low frequency fluctuations in the level of the equilibrium real rate, as would the hypothesis of a nonstationary NRI also do. Nevertheless, assuming that the NRI follows a nonstationary process hinders the economic interpretation of the model, in particular if we assume, as suggested by economic theory, that potential growth $\Delta y_{t}^{*}$ shares common fluctuations with $r_{t}^{*}$.

Indeed, the economic intuition underlying our specification choice in equations (3) to (5) refers to a basic optimal growth set-up (the textbook Ramsey model), where intertemporal utility maximisation by the representative household yields the following log-linear relationship between the real interest rate and the growth rate of per capita consumption:

$$
r_{t}=\theta g_{C}(t)+\rho
$$

This relationship relies notably on the assumption of a standard utility function of the representative household $u\left(C_{t}\right)=C_{t}^{1-\theta} /(1-\theta)$ with constant relative risk aversion $\theta$ (which corresponds to the inverse of the intertemporal elasticity of substitution) and where $\rho$ stands for the rate of time preference of consumers. Textbook presentations of the Ramsey model express the rate of growth of per capita consumption as the sum of the (exogenous) constant rate of laboraugmenting technological change and the rate of growth of consumption per unit of effective labor. The latest is null along a balanced-growth path. From this simple framework, we get a relationship similar to equation (8) between the equilibrium real rate of interest and the (usually constant) rate of laboraugmenting technological change, which is also the rate of growth of per capita output along a balanced-growth path. Assuming then that this trend growth rate $g$ is in fact subject to low frequency fluctuations, we get the intuition underlying our specification choice, namely:

$$
r_{t}^{*}=\theta g_{t}+\rho
$$

where $g_{t}$ is equivalent to our $\theta_{y} a_{t}$. The (highly) autoregressive process denoted by $a_{t}$ aims hence at capturing low-frequency variations in potential output growth, under the assumption that these variations are common with those

\footnotetext{
${ }^{4}$ See e.g. Laubach and Williams (2003), Orphanides and Williams (2002), or Larsen and McKeown (2002).

${ }^{5}$ A nonstationary specification for the NRI and then potential output growth -through the assumption of a random-walk for $a_{t}$ - would indeed imply that potential output is integrated of order two, which would be at odds with available evidence for the euro area. Besides, when translated into the set-up of a standard optimal growth model, this would mean a nonstationary path for the ratio of output to the stock of capital.
} 
of the NRI. In addition to this persistent but stationary process, potential output growth consists in our model of another stationary component, which may account for other sources of discrepancies with the natural rate of interest -e.g. due to shocks to preferences or changes in fiscal policies. Estimations show that a simple white noise is sufficient to model this stationary component ${ }^{6}$. These specifications assume that potential GDP is an I(1) process, as is usual for the euro area ${ }^{7}$.

Our specifications attempt to model the links between potential output growth and the natural rate of interest. In this respect, our approach lies between these of Laubach and Williams (2003) and of Orphanides and Williams (2002). In the former, $r_{t}^{*}$ is the sum of the trend growth rate, which also drives the low-frequency fluctuations of potential output growth, and of a second specific (possibly nonstationary) component. In the latter study, the natural rate of interest and potential output growth are completely uncorrelated. This last assumption appears at odds with theoretical intuition and may potentially results in non-optimal exploitation of the data. Laubach and Williams' approach features a higher level of complexity and therefore appears more attractive. However, this complexity raises numerous estimation problems, notably because it means extracting two unobservable components out of an already unobservable variable $\left(r_{t}^{*}\right)$ which in turn is identified through the dynamics of an other unobservable variable $\left(z_{t}\right)^{8}$. Since we aim precisely at estimating a TVNRI in a way as transparent and robust as possible, we prefer to consider a singleprocess-driven NRI, yet presenting common fluctuations with potential output growth.

\section{Estimation}

The previous equations can be written in the state-space form, and the parameters can be estimated by maximisation of the likelihood function provided by the Kalman filter (see Annex D for the state-space representation of the present model). This filter is a recursive algorithm for sequentially updating a linear projection for a dynamic system. Given a set of measurement and transition equations, the Kalman filter provides the best linear unbiased estimator of the state variables (filtered or smoothed ${ }^{9}$ ) and a particularly attractive feature of

\footnotetext{
${ }^{6} \mathrm{AR}$ specifications systematically lead to non-significant autoregressive coefficients.

${ }^{7}$ See for example Gerlach and Smets (1998). Besides, both the ADF and Phillips-Perron tests clearly reject the null hypothesis of an I(2) log real GDP.

${ }^{8}$ In particular, some estimates of key-parameters when several components enter the dynamics of the NRI are very sensitive to the initial state values and variances. More precisely, if the NRI is assumed to follow a two-component process $\left(r_{t}^{*}=\theta_{r} a_{t}+\eta_{t}\right)$ and if the variance reflecting the confidence on the initial value $\eta_{0}$ is not large enough, the parameter $\theta_{r}$ might be bounded to estimate the initial level of the NRI instead of assessing the extent to which the NRI and potential output growth fluctuate together. Modelling the dynamics of the NRI using a single component (and playing down level-estimation problems by demeaning the involved series) appears to be an efficient and tractable way of avoiding such misleading estimations.

${ }^{9}$ A filtered estimate is one-sided - that is, it uses information only up to time t. A smoothed estimate is two-sided and uses information from the whole sample, up to time $T$. In this
} 
this approach is its ability to quantify uncertainty around the estimated state variables ${ }^{10}$. Two classical estimation issues related to Kalman filter techniques are discussed below, namely the choice of the initial values of the state vector and the estimation of the innovation variances.

Estimation by the Kalman recursive equations requires the setting of initial values for the state vector, which comprises two blocks relative to $a_{t}$ (and its first lag) on the one hand and to the output gap $z_{t}$ (and its first lag) on the other. Natural candidates for the initial conditions are the unconditional mean and autocovariances of the unobservable variables in each block. Since we have not specified any equation for the dynamics of the nominal interest rate (in other words the reaction function of the central bank remains implicit), the derivation of the unconditional mean and variance of the output gap $z_{t}$ remains however out of reach. We hence resort to a common practice which consists in adopting relatively diffuse priors and assuming sufficiently large values for the unobserved variance matrix (which measures the confidence in the priors). More precisely, we use the HP filter to get a prior estimate of the output gap. The filtered series is then used to get initial values for $z_{t}$ as well as to derive the output gap block of the covariance matrix of the initial state vector. By contrast, it is straightforward from equation (5) to derive the unconditional mean and autocovariances of the AR process $a_{t}$ as a function of the parameters. The maximisation of the log-likelihood computed by the Kalman filter then yields simultaneously the vector of parameters and the initial conditions for $a_{t}$.

The so-called "pile-up problem" prevents from estimating efficiently some parameters by direct maximization of the log-likelihood: this means that estimates of low true variances of the innovations entering the unobservable variables dynamics are biased towards zero because a large amount of probability in their distributions piles-up at zero ${ }^{11}$. A correct answer is the median-unbiased estimator method developed by Stock and Watson (1998) which consists in estimating in a first step signal-to-noise ratios and in imposing these in a second estimation step. Laubach and Williams (2001) follow this approach but find wide confidence interval around the ratios, which plays down the interest of such a method. Following King and al. (1995), Staiger and al. (1997) or Laubach (2000), we prefer an alternative transparent and commonly used practice consisting in fixing signal-to-noise ratios.

Two ratios are thus considered in the following: $\sigma_{y} / \sigma_{z}$ (denoted with $\gamma_{1}$ ) and $\theta_{r} / \theta_{y}$ (denoted with $\gamma_{2}$ ). As illustrated in Table 1 , no consensus on the

\footnotetext{
respect, the HP filter is a smoother, since it can be thought of as a two-sided moving average.

${ }^{10}$ As pointed out by Hamilton (1986), two forms of uncertainties are associated with the estimated state vector of a state-space model. The first one, the "filter uncertainty", reflects the fact that the estimated state vector represents conditional expectations of true unobserved values. This first uncertainty is due to Kalman filter estimation and would be present even if the true value of the model parameter were known. The second one, the "parameter uncertainty" reflects the uncertainty around the estimated parameters.

${ }^{11}$ The "pile-up problem" stems from discontinuity in the distribution of the state variable. Typically, let $u_{t}$ be a state variable assumed to follow a random walk without drift. If the variance of its innovation is equal to zero, $u_{t}$ is stationary (in fact a constant) and this explains the discontinuity in the distribution function.
} 
$\gamma_{1}$ ratio can be reached among estimation results for similar models of the US and EU economies ${ }^{12}$. On the one hand -and due to our specifications- this ratio should not be too small because this would amount to impose the strong hypothesis that the natural rate of interest and potential output growth have exactly the same fluctuations. Indeed, potential output growth would then reduce to $\theta_{y} a_{t}$, which turns out to be equal to $\theta_{y} / \theta_{r} r_{t}^{*}$. On the other hand, too large a ratio entails a potential output growth very close to the observed GDP growth. Besides, the larger $\gamma_{1}$, the more volatile is potential output growth and the less volatile the output gap. To the extent that we prefer the output gap to be more volatile than potential output growth, we should choose a value for $\gamma_{1}$ below unity.

\begin{tabular}{|c|c|c|c|c|c|c|c|c|}
\hline \multicolumn{9}{|c|}{ Table.1 Estimation results from various studies } \\
\hline Auth. & area & period & $\overline{\sigma_{\pi}}$ & $\overline{\sigma_{z}}$ & $\overline{\sigma_{y}}$ & $\overline{\sum \Phi_{i}}$ & $\overline{\bar{\lambda} \lambda}$ & $\overline{\bar{\beta}}$ \\
\hline MR & $E A$ & 1979:1-2002:4 & 0.97 & 0.37 & 0.18 & 0.80 & $\begin{array}{l}-0.06 \\
\times 2 \text { lags }\end{array}$ & 0.19 \\
\hline FM & $E A$ & 1970:1-1999:3 & 0.79 & 0.48 & 0.20 & 0.97 & 1 & 0.12 \\
\hline PS & $\underset{(5)}{E U}$ & 1975:1-1997:4 & 0.99 & 0.47 & 0.44 & 0.94 & -0.10 & 0.33 \\
\hline GS & $\begin{array}{l}E U \\
(5)\end{array}$ & 1975:1-1997:4 & 1.01 & 0.65 & 0.00 & 0.95 & -0.08 & 0.18 \\
\hline GS & $\underset{(5 / 10)}{E U}$ & $1975: 1-1997: 4$ & 0.91 & 0.63 & 0.00 & 0.96 & -0.09 & 0.19 \\
\hline GS & $\underset{(5)}{E U}$ & 1990:1-1997:4 & 0.91 & 0.41 & 0.00 & 0.89 & -0.02 & 0.30 \\
\hline GS & $\begin{array}{l}E U \\
(10)\end{array}$ & 1990:1-1997:4 & 0.69 & 0.35 & 0.00 & 0.90 & -0.05 & 0.14 \\
\hline PS & $U S$ & 1975:1-1997:4 & 0.86 & 0.37 & 0.62 & 0.89 & -0.12 & 0.11 \\
\hline $\mathrm{RS}$ & $U S$ & 1961:1-1996:2 & 1.01 & 0.82 & 0.00 & 0.91 & -0.10 & 0.14 \\
\hline $\mathrm{S}$ & $U S$ & 1962:1-1997:4 & 1.08 & 0.22 & 0.73 & 0.94 & -0.06 & 0.21 \\
\hline $\mathrm{S}$ & $U S$ & 1980:1-1997:4 & 0.64 & 0.20 & 0.47 & 0.93 & -0.07 & 0.23 \\
\hline LW & $U S$ & 1961:1-2000:4 & 0.73 & 0.35 & 0.63 & 0.94 & -0.10 & 0.04 \\
\hline
\end{tabular}

Table 1: MR : Mésonnier and Renne, this paper / PS : Peersman and Smets (1999) / GS : Gerlach and Smets (1999) / S : Smets (2000) / RS : Rudebusch and Svensson (1998) / LW : Laubach and Williams (2001) / FM : Fabiani and Mestre (2004, model 1)

Without additional constraint, $\theta_{y}$ is spontaneously estimated to be zero, suggesting that there is no common trend between the natural rate of interest and potential output growth. However, Figure 1 plots the natural rate of interest -resulting from such an estimation- together with the HP-filtered output growth and shows that the series exhibit marked common fluctuations ${ }^{13}$. It can consequently be assumed that information contained in the data is not optimally extracted by direct MLE and that the null estimate of $\theta_{y}$ stems from a pile-up-like phenomenon. For this reason, we resort to a calibration of the ratio

\footnotetext{
${ }^{12}$ In Table 1 , estimates of $\sigma_{y} / \sigma_{z}$ ranges from approximately 0 to 3 .

13 The correlation coefficient of the two series is 0.80 .
} 
$\theta_{r} / \theta_{y}$. Available empirical evidence suggests that the natural rate of interest varies from one-for-one to five-for-one with changes in the trend growth rate $\mathrm{e}^{14}$. As a result, we consider such an interval for the ratio $\theta_{r} / \theta_{y}$ in the following ${ }^{15}$.

\section{$5 \quad$ Estimation results}

As regards the Phillips curve, the choice of the order of the lag-polynomial $A(L)$ is based on the significance of the last lag included. Moreover, the null hypothesis that the coefficients of the inflation lags sum to one is not rejected by the data, leading to an accelerationist form of the Phillips curve. In other words, inflation depends only on nominal factors in the long run. As regards the IS equation, only the first lag of the output gap is included ${ }^{16}$. In addition, following Laubach and Williams, two lags of the rate gap enter this equation. However, since the estimation of two distinct coefficients for each of these two lags results in some unsatisfying compensation phenomena, we constrain the two coefficients to be equal. The model can then be rewritten:

$$
\begin{aligned}
\pi_{t+1} & =\alpha_{1} \pi_{t}+\alpha_{2} \pi_{t-1}+\alpha_{3} \pi_{t-2}+\beta z_{t}+\varepsilon_{t+1}^{\pi} \\
z_{t+1} & =\Phi_{1} z_{t}+\Phi_{2} z_{t-1}+\lambda(1+L)\left(i_{t}-\pi_{t+1 \mid t}-r_{t}^{*}\right)+\varepsilon_{t+1}^{z} \\
r_{t}^{*} & =\mu_{r}+\theta_{r} a_{t} \\
\Delta y_{t}^{*} & =\mu_{y}+\theta_{y} a_{t}+\varepsilon_{t}^{y} \\
a_{t+1} & =\psi a_{t}+\varepsilon_{t+1}^{a} \\
y_{t} & =y_{t}^{*}+z_{t}
\end{aligned}
$$

The numerical BFGS algorithm provided by GAUSS is applied to get the MLE $^{17}$, under fixed $\gamma_{1}=\sigma_{y} / \sigma_{z}$ and $\gamma_{2}=\theta_{r} / \theta_{y}$. The choice of these ratios is based on three criteria:

- first, the Lagrange Multiplier test, whose main advantage is that the unrestricted MLE does not need to be known, is applied for many values of the ratios $\left(\left\{\gamma_{1}, \gamma_{2}\right\} \in[0,3] \times[4,20]\right)$ and combinations leading to a $p$-value lower than $25 \%$ are rejected;

\footnotetext{
${ }^{14}$ Intertemporal elasticities of substitution (IES) estimated by Hall (1988) are small and not statistically different from zero (corresponding to infinite risk aversion). However, Ogaki and Reinhart (1998) argue that Hall's model is misspecified because the intratemporal substitution between nondurable consumption goods and durable consumption goods is ignored and in two contributions $(1998 \mathrm{a}, 1998 \mathrm{~b})$, they obtain IES estimates between 0.27 and 0.77 (corresponding to risk aversions between 1.3 and 3.7). Barsky et al. use micro-data and estimate an IES of 0.18 , implying a coefficient of risk aversion of 5.5.

${ }^{15}$ Since we use quarterly growth rate of GDP, a relative risk aversion coefficient of 1 corresponds here to a value of 4 for the ratio $\theta_{r} / \theta_{y}$. That is why the interval considered for this ratio is $[4,20]$.

${ }^{16}$ Including a second lag yields a small and non-significant second autoregressive parameter.

${ }^{17}$ As regards the initialization of the optimisation algorithm, many starting values have been tested: our estimates appear to be particularly robust to their choice.
} 
- the economic relevance of the estimated unobservable components and the significativity of the main parameters of our model constitutes a second criterion;

- the level of implied uncertainty inherent to the Kalman filtering procedure is the third one.

Results according to the first criterion $^{18}$ are presented on Figure 2, and suggest that $\gamma_{1}$ should be chosen lower than 2 and $\gamma_{2}$ greater than 8 .

\begin{tabular}{c|cccccc}
\hline \hline \multicolumn{7}{c}{ Table.2 Parameter estimates } \\
\hline \hline & $\gamma_{1}=0.5$ & $\gamma_{1}=0.5$ & $\gamma_{1}=0.5$ & $\gamma_{1}=\sqrt{0.1}$ & $\gamma_{1}=1.5$ & $\gamma_{1}=0.5$ \\
& $\gamma_{2}=12$ & $\gamma_{2}=16$ & $\gamma_{2}=20$ & $\gamma_{2}=16$ & $\gamma_{2}=16$ & $\gamma_{2}=\infty$ \\
\hline LF & -200.61 & -200.34 & -200.16 & -200.35 & -200.23 & -199.58 \\
\hline avg SE & 0.97 & 1.12 & 1.24 & 1.08 & 1.41 & 2.81 \\
\hline$\alpha_{1}$ & 0.47 & 0.46 & 0.46 & 0.47 & 0.43 & 0.44 \\
& $(4.8)$ & $(4.8)$ & $(4.7)$ & $(4.8)$ & $(4.4)$ & $(4.5)$ \\
\hline$\alpha_{2}$ & 0.27 & 0.27 & 0.27 & 0.27 & 0.28 & 0.28 \\
& $(2.6)$ & $(2.6)$ & $(2.6)$ & $(2.6)$ & $(2.7)$ & $(2.7)$ \\
\hline$\alpha_{3}$ & 0.26 & 0.27 & 0.27 & 0.26 & 0.29 & 0.28 \\
& $(2.6)$ & $(2.7)$ & $(2.7)$ & $(2.7)$ & $(2.9)$ & $(2.8)$ \\
\hline \multirow{2}{*}{$\beta$} & 0.19 & 0.19 & 0.19 & 0.18 & 0.30 & 0.12 \\
& $(1.8)$ & $(1.9)$ & $(2.0)$ & $(1.9)$ & $(1.8)$ & $(1.7)$ \\
\hline$\sigma_{\pi}$ & 0.97 & 0.97 & 0.97 & 0.97 & 0.95 & 0.97 \\
& $(13.7)$ & $(13.7)$ & $(13.7)$ & $(13.8)$ & $(13.5)$ & $(13.6)$ \\
\hline \multirow{2}{*}{$\Phi$} & 0.79 & 0.80 & 0.80 & 0.80 & 0.76 & 0.85 \\
& $(4.8)$ & $(4.9)$ & $(5.1)$ & $(5.1)$ & $(4.1)$ & $(4.8)$ \\
\hline$\lambda$ & -0.06 & -0.06 & -0.06 & -0.06 & -0.05 & -0.04 \\
& $(-1.5)$ & $(-1.5)$ & $(-1.5)$ & $(-1.5)$ & $(-1.2)$ & $(-1.1)$ \\
\hline$\sigma_{z}$ & 0.37 & 0.37 & 0.37 & 0.39 & 0.24 & 0.37 \\
& $(8.2)$ & $(8.2)$ & $(8.2)$ & $(7.9)$ & $(9.9)$ & $(7.8)$ \\
\hline$\psi$ & 0.89 & 0.90 & 0.90 & 0.90 & 0.89 & 0.90 \\
& $(9.1)$ & $(9.5)$ & $(9.7)$ & $(9.6)$ & $(8.1)$ & $(6.5)$ \\
\hline$\sigma_{y}$ & 0.18 & 0.18 & 0.18 & 0.12 & 0.36 & 0.18 \\
& $(8.2)$ & $(8.2)$ & $(8.2)$ & $(7.9)$ & $(9.9)$ & $(7.8)$ \\
\hline$\mu_{y}$ & 0.52 & 0.52 & 0.52 & 0.52 & 0.53 & 0.53 \\
& $(7.6)$ & $(8.4)$ & $(9.2)$ & $(8.6)$ & $(7.3)$ & $(19.7)$ \\
\hline$\theta_{y}$ & 0.07 & 0.06 & 0.05 & 0.06 & 0.07 & 0 \\
& $(1.7)$ & $(1.7)$ & $(1.6)$ & $(1.7)$ & $(1.6)$ & \\
\hline$\mu_{r}$ & 3.12 & 3.10 & 3.07 & 3.09 & 3.14 & 3.40 \\
& $(2.4)$ & $(2.2)$ & $(2.0)$ & $(2.2)$ & $(2.3)$ & $(1.8)$ \\
\hline$\theta_{r}$ & 0.87 & 0.98 & 1.07 & 0.98 & 1.13 & 2.28 \\
& $(1.7)$ & $(1.7)$ & $(1.6)$ & $(1.7)$ & $(1.6)$ & $(1.0)$ \\
\hline & & & & & & \\
\hline
\end{tabular}

Table 2: LF: likelihood Function - t-students in parenthesis - avg SE: average of the estimated standard error around the estimate of the natural rate of interest (filter uncertainty)

Table 2 contains the parameter estimates when $\gamma_{1}$ is equal to 0.5 and $\gamma_{2}$ to

\footnotetext{
${ }^{18}$ For a given level of $\gamma_{1}$, taken in the range of accepted values according the LM test, a likelihood-ratio test rejects the null-hypothesis corresponding to a given level of $\gamma_{2}$ when this last ratio is below a certain threshold. For $\gamma_{1}$ equal to 0.5 , this threshold for $\gamma_{2}$ is 7 with a probability of error of $10 \%$. Hence, the likelihood-ratio test does not help to discriminate further between the values of $\gamma_{2}$ reported in Table 2 .
} 
different values $(12,16,20$ or $\infty)$; and when $\gamma_{2}$ is equal to 16 and $\gamma_{1}$ is equal to $\sqrt{0.1}$ or 1.5. The computation of the information matrix is based on the expression given by Engle and Watson (1981) (see Annex C). All the parameters have the expected sign. The "monetary policy transmission parameters" -namely $\beta$, the slope of the Phillips curve and $\lambda$, the IRG semi-elasticity of the output gap- are in line with the estimates obtained in close models for the European Union (see Table 1) ${ }^{19}$. Furthermore, the significativity of both the slope of the Phillips curve and the IRG semi-elasticity of the output gap compares broadly with those of Laubach and Williams ${ }^{20}$. As a rule, except for the standard deviations, the parameter estimates are little affected by the choice of the ratios. Increasing $\gamma_{1}$ tends to deteriorate the significativity of $\lambda$, while only slightly diminishing this of $\beta$. Turning to the second ratio, an increase in $\gamma_{2}$ pulls down the significativity of $\theta_{r}$ which is key for our estimate of the natural rate of interest. Moreover, the larger is $\gamma_{2}$, the wider the confidence interval around the natural rate of interest grows but at the same time the greater is the log-likelihood. Finally, Figures 3 and 4 suggest that the estimates of the state variables are faintly sensitive to the $\operatorname{ratios}^{21}$. For all this, our preferred ratios are the following:

$$
\gamma_{1}=\frac{\sigma_{y}}{\sigma_{z}}=0.5 \text { and } \gamma_{2}=\frac{\theta_{r}}{\theta_{y}}=16
$$

Figure 5 plots our estimated smoothed natural rate of interest, together with the actual real rate of interest and the $90 \%$ confidence interval around the estimates of state variables. The estimated real interest rate gap offers a valuable insight into the monetary policy stance over the last two decades. Indeed, a positive interest rate gap means that monetary policy aims at dampening the current rate of inflation. Conversely, a negative gap means that the level of the central bank's key rate gives leeway to a rise in inflation. For convenience's sake, we describe here both situations in terms of monetary policy being either "tight" or "loose". However, a more precise terminology would refer to a "disinflationary" versus an "inflationary" policy stance. The point at stake is that the real interest rate gap is not conceptually equivalent to the differential between the (policy driven) real interest rate and the short term real rate that a standard Taylor rule would prescribe. While the interest rate prescription of the Taylor rule aims at anchoring inflation at a given level (the "inflation target" of the central bank), equating the current real rate of interest with its "natural" counterpart only means that one has an objective of inflation stabilisation, but nothing is said about the nominal anchor.

\footnotetext{
${ }^{19}$ The effect of the interest rate gap on the output gap is indeed twice larger than $\lambda$ since we consider two lags of the real rate gap in the IS curve with this same coefficient.

${ }^{20}$ The p-values associated with the Student $\mathrm{T}$ for our parameters $\beta$ and $\lambda$ are $5 \%$ and $13 \%$ respectively. In their baseline model for the United States, Laubach and Williams get p-values of $10 \%$ and $0 \%$ for the same parameters.

${ }^{21}$ Larger swings are observable in the case $\gamma_{2}=\infty$. However, as previously said, this value corresponds to the case where the trend growth rate and the NRI do not have any common stochastic trend, which is unsatisfying from an economic point of view.
}

- insert Figure 5 here -

- insert Figure

6 here -

- insert Figure

7 here - 
This being said, according to our measure of the real interest rate gap and taking into account filter-uncertainty, monetary policy in the euro area appears to have been significantly "tight" over four particular episodes: in 1981-1982 in parallel with the "Volcker era" in the United States, during the second half of 1984, around the EMS crisis of summer 1992 and lastly, in 1995. Conversely, three episodes of significantly "loose" monetary policy are identified, namely in the late 1970s during the "great inflation" and before the vigorous tightening of the early 1980s, in 1988 while the output gap of the area was rapidly reverting, and finally in 1999, mainly as a consequence of the 50 bp cut in the ECB's repo rate in April. From 2000 on, the actual real short term rate of interest appears by contrast to be fairly in line with its estimated natural counterpart, which suggests that the monetary policy stance in the euro area has been broadly appropriate since then in terms of inflation stabilisation.

Turning to the output gap, Figure 6 highlights periods of excess demand around 1980, 1990 and 2000 and periods of excess supply in the mid-1980s and mid-1990s. Resulting peaks and troughs are in line with available evidence about the business cycle in the main European countries over the last two decades. The $a_{t}$ component satisfyingly tracks the low-frequency fluctuations of potential output growth (see Figure 7) and can therefore be interpreted as the trend growth rate specified in Laubach and Williams (2001) once multiplied by $\theta_{y}$. According to our results, potential output growth would have reached a maximum of $3.2 \%$ in 1989 and a minimum of $1.6 \%$ in 1982 and 2002. This final low value of the trend growth rate partly accounts for the positive output gap at the end of the sample. Indications of such a recent decrease in the trend growth rate for the euro area are in turn consistent with empirical evidence of a slowdown in trend productivity growth in European countries in the 1990s (Maury and Pluyaud, 2004), together with the postulated end of the catching up process of American productivity levels in the mid-1990s.

A proxy for the real-time estimate of the NRI is the filtered value yielded by the Kalman filter, which uses information available up to time $t$ only (instead of $\mathrm{T}$ for the smoothed value $)^{22}$. Figure $\mathbf{8}$ shows that the differences between the filtered and smoothed series of the NRI are relatively small. Both resulting interest rate gaps present roughly the same sign throughout the period. Nevertheless, the gap derived from the filtered series tends to change signs after its smoothed equivalent, which is in any case not surprising considering the information advantage of the smoothed series.

Finally, different filtering techniques are compared in Figure 9. Two univariate filters have been used: the Hodrick-Prescott (HP) filter (1997) and the Band-Pass (BP) filter (see Baxter and King, 1999). As regards the HP filter, two smoothness parameters are considered: 1600 and $7000^{23}$. Following Staiger,

\footnotetext{
${ }^{22}$ As previously stated, this estimate is not rigorously available in real-time because it relies on estimated values for the parameters of the state-space model, which are computed on the basis of the whole sample information.

${ }^{23}$ This last value smoothes the data slightly more than the commonly-used 1600 value. Bouthevillain et al. (2001) show that this value entails significant benefits in terms of less leakage effects (which is a filtering "error" corresponding to the overestimation of the variabil-
}

- insert Figure

8 here - 
Stock and Watson (2002), as well as Laubach and Williams (2003), the BP filter is used to discard the cyclical component from the real rate of interest, i.e. the frequencies corresponding to periods of up to 15 years. Consistently with their two-sided moving average representations (finite in the case of the Baxter and King BP filter, infinite in the case of the HP filter), the two univariate filters simply track the trend of the real rate of interest, while our estimate also takes into account the actual fluctuations in inflation and the level of output. More precisely, as Figure 10 shows, a positive sign of our real rate gap is contemporaneous with periods of marked disinflation while a significant negative sign of our real rate gap entails a rise in inflation over the same period. Besides, a persistent slowdown of the trend growth rate results as expected in a decrease in the natural rate of interest.

To comment further on the relationship between the interest rate gap and inflation in the euro area, it is convenient to decompose the changes in our estimated real rate gap into three components: $1 /$ changes in the nominal interest rate, $2 /$ changes in one-quarter-ahead inflation expectations and $3 /$ changes in the NRI itself. Figure 11 displays this breakdown together with the corresponding interest rate gap. According to common economic intuition, it appears then for instance that the strongly positive real rate gap that occurred in the early 1980 s was the result of a steep increase $(2 \%)$ in the nominal short term rate in 1981Q2. The quarters that followed saw a slow narrowing of the gap: the fall in the nominal interest rate added to the rise in the natural rate of interest was slightly larger than the decrease in short term inflation expectations. By 1987Q2, the gap had reached negative levels. Meanwhile, inflation as well as short term inflation expectations, which continuously decreased over the period 1981-1986, rebounded in 1987-1989, thus largely contributing to the widening gap. The 1992 peak of the interest rate gap seems to be explained by both a marked increase of the NRI over 1991 and 1992 and a strong rise in the nominal short term rate consecutive to the EMS crisis of September 1992. The chart further suggests that, with the disinflation process being largely completed after that episode, the then observed decreasing trend in the interest rate gap must be attributed mainly to a series of cuts in the nominal interest rates prior to entry into EMU in 1999.

\section{Conclusion}

In this paper, we have estimated a time-varying natural rate of interest (TVNRI) for the euro area considered as a single entity over the period 1979-2002. Our approach closely follows the methodology recently developed by Laubach and Williams (2003) for the United States. Indeed, the Kalman filter is used to estimate a backward-looking state-space model which encompasses a Phillipscurve and an aggregate demand equation. The TVNRI belongs to the vector of

ity of the cyclical component) compared to the costs related to the increase in compression effects (which is the alternative filtering "error").
- insert Figure 10 here - insert Figure 11 here - 
unobserved variables, along with the output gap. However, our specifications depart from Laubach and Williams', notably in that we assume a stationary process for the rate of growth of potential output instead of an I(1) process and use model-consistent inflation expectations to compute the ex ante real rate of interest instead of a proxy for inflation expectations as generated from an univariate model of inflation.

The conducted empirical analysis provides evidence that our estimates are robust to changes in calibrated variables. Besides, the postulated strong relationship between the TVNRI and the low-frequency fluctuations of potential output growth appears to be well-supported by the data. We obtain estimates of the real interest rate gap that offer a valuable insight into the monetary policy stance over the last two decades. According to our results and focusing for instance on the last few years only, the monetary policy stance of the ECB appears then to have been significantly loose in 1999, but the non-significant interest rate gap after that year would indicate that it has been broadly appropriate since then in terms of stabilising inflation.

As a complement to our study, optimal policy issues could be raised within this framework. In particular, an advantage of the method used lies in the possibility to evaluate the uncertainty surrounding the unobserved variables, which allows to conduct a study of the robustness of monetary policy rules to such estimation uncertainty. However, this is left for further research. 


\section{Bibliography}

Barsky, R.B., Juster, F.T., Kimball, M.S., Shapiro, M.D., 1997. Preference parameters and behavioral heterogeneity: an experimental approach in the health and retirement study. The Quarterly Journal of Economics, May 1997.

Basdevant, O., Björksten, N., Karagedikli, Ö, 2004. Estimating a timevarying neutral real interest rate for New Zealand. Reserve Bank of New Zealand, DP2004/01.

Baxter, M., King, R.G., 1999. Measuring Business Cycles: Approximate Band-Pass Filters for Economic Time Series. The Review of Economic and Statistics 81 (4), 575-593.

Bernanke, B., Mihov, I., 1998. Measuring Monetary Policy. Quarterly Journal of Economics 113, 869-902.

Blinder, A., 1998. Central Banking in Theory and Paractice. The MIT Press, Cambridge.

Bouthevillain, C., Cour-Thimann, P., van den Dool, G., Hernandez de Cos, P., Langenus, G., Mohr, M., Momigliano, S., Tujula, M., 2001. Cyclically adjusted budget balances: an alternative approach. Working Paper $n^{\circ} 77$, European Central Bank.

Brzoza-Brzezina, M., 2003. Estimating the Natural Rate of Interest: a SVAR approach. Paper $n^{\circ}$ 27, National Bank of Poland.

Chadha, J.S., Nolan, C., 2001. Supply Shocks and the 'Natural Rate of Interest': an Exploration. Cambridge Working Paper in Economics, $n^{\circ} 0103$.

Archibald, J., Hunter L., 2001. What is the neutral real interest rate, and how can we use it? Reserve Bank of New Zealand, Bulletin vol.64, $n^{\circ} 3$, September 2001.

Christensen, A.M., 2002. The Real Interest Rate Gap: Measurement and Application. Danmarks Nationalbank, Working Paper $\mathrm{n}^{\circ} 2002-6$.

Crespo Cuaresma, J., Gnan, E., 2003. Searching for the Natural Rate of Interest: a Euro-Area perspective. Working Paper $n^{\circ} 84$, Oesterreichische Nationalbank.

Dennis, R., 2001. The Policy Preferences of the U.S. Federal Reserve. Federal Reserve Bank of Chicago, Working Paper Series, $n^{\circ} 01-08$.

Dotsey, M., Scholl, B., 2003. The Behavior of the Real Rate of Interest. Journal of Money, Credit and Banking, vol. 35 (1), 91-110. 
ECB, 2004. The Natural real interest rate in the euro area. ECB monthly Bulletin, May 2004.

Engle, R.F., Watson, M., 1981. A One-factor Multivariate Time Series Model of Metropolitan Wage Rates. Journal of the American Statistical Association, $76, \mathrm{n}^{\circ} 376,774-781$.

Estrella, A., Fuhrer, J.C., 1999. Are 'Deep' Parameter Stable? The Lucas Critique as an Empirical Hypothesis. Society for Computational Economics, $n^{\circ} 621$.

Fabiani, S., Mestre, R., 2004. A system approach for measuring the Euro area NAIRU. Empirical Economics, vol.39 (2).

Fagan, G., Henry, J., Mestre, R., 2001. An Area-Wide Model (AWM) for the Euro Area. Working Paper ${ }^{\circ} 42$, European Central Bank.

Gerlach, S., Smets, F., 1999. Output Gaps and Monetary Policy in the EMU area. European Economic Review, 43, 801-812.

Giammarioli, N., Valla, N., 2003. The natural real rate of interest in the euro area. Working Paper $n^{\circ} 233$, European Central Bank.

Gordon, R., 1997. The Time Varying NAIRU and Its Implications for Economic Policy. Journal of Economic Perspectives, 11 (1), 11-32.

Hall, R.E., 1988. Intertemporal Substitution in Consumption. Journal of Political Economy, vol.96, ${ }^{\circ} 2$.

Hamilton, J., 1986. A Standard Error for the Estimated State Vector of a State-Space Model. Journal of Econometrics, 1986, 33, 387-397.

King, R., Stock, J., Watson, M., 1995. Temporal Instability of the UnemploymentInflation Relationship", Economic Perspective of the Federal Reserve bank of Chicago, 19, 2-12.

Larsen, J.D.J. and Mckeown, J., 2002. The informational content of empirical measures of real interest rate and output gaps from the United Kingdom. prepared for the BIS autumn 2002 workshop on "Monetary policy in a changing environment". BIS paper $\mathrm{n}^{\circ} 19$.

Laubach, T., 2001. Measuring the NAIRU: Evidence from Seven Economies. Review of Economics and Statistics, May 2001, 83 (2), 218-231.

Laubach, T., Williams, J.C., 2003. Measuring the Natural Rate of Interest. The Review of Economics and Statistics, November 2003, 85(4), 1063-1070. 
Leeper, E., Zha, T., 2002. Empirical Analysis of Policy Interventions. National Bureau of Economic Research, $\mathrm{n}^{\circ} 9063$.

Maury, T.P., Pluyaud, B., 2004. The Breaks in per Capita Productivity Trends in a Number of Industrial Countries. Banque de France, Note d'Etudes et de Recherche $n^{\circ} 111$.

Neiss, K.S., Nelson, E., 2001. The real interest rate gap as an inflation indicator. CEPR discussion paper series, $\mathrm{n}^{\circ} 2848$.

Ogaki, M., Reinhart, C.M., 1998a. Intertemporal substitution and durable goods: long-run data. Economics Letters, 61, 85-90.

Ogaki, M., Reinhart, C.M., 1998b. Measuring Intertemporal Substitution: The Role of Durable Goods. Journal of Political Economy, vol. 106, $\mathrm{n}^{\circ} 5$.

Onatski, A., Stock, J., 2002. Robust Monetary Policy Under Model Uncertainty in a Small Model of the U.S. Economy. Macroeconomic Dynamics 66, 85-110.

Orphanides, A., Williams, J.C., 2002. Robust Monetary Policy Rules with Unknown Natural Rates. Brookings Papers on Economic Activity 2(2002), 63145 .

Peersman, G., Smets, F., 1999. The Taylor rule, a useful monetary policy benchmark for the Euro area?. International Finance, No. 1, p 85-116.

Rudebusch, G.D., 2002. Assessing the Lucas Critique in Monetary Policy Models. Working Papers in Applied Economic Theory, Federal reserve Bank of San Francisco, $\mathrm{n}^{\circ}$ 2002-02.

Rudebusch, G.D., Svensson, L.E.O., 1998. Policy Rules for Inflation Tageting. National Bureau of Economic Research, Working Paper Series n ${ }^{\circ} 6512$.

Rudebusch, G.D., Svensson, L.E.O., 2002. Eurosystem Monetary Targeting: Lessons from U.S. Data. European Economic Review 46, 417-442.

Smets, F., 1998. Output Gap Uncertainty: Does It Matter for the Taylor Rule?. BIS Working Papers, nº6, November 1998.

Smets, F., Wouters, R., 2002. Output and interest rate gaps: Theory versus practice. Society for Computational Economics, Computing in Economics and Finance, $n^{\circ} 355$.

Söderström, U., Söderlind, P., Vredin, A., 2003. New-Keynesian Models and Monetary Policy: A Reexamination of the Stylized Facts. Working Papers Series in Economics and Finance, Stockholm School of Economics, $n^{\circ} 511$. 
Staiger, D., Stock, J., Watson, M., 1997. The NAIRU, Unemployment, and Monetary Policy. Journal of Economic Perspectives, 11 (1997a), 33-49.

Stock, J.H., Watson, M.W., 1996. Evidence on Structural Instability in Macroeconomic Time Series Relations. Journal of Business and Economic Statistics, vol.14, 11-30.

Stock, J.H., Watson, M.W., 1998. Median Unbiased Estimation of Coefficient Variance in a Time-Varying Parameter Model. Journal of the American Statistical Association, March 1998, 93, 349-358.

Taylor, J.B., 1993. Discretion versus policy rules in practice. CarnegieRochester Conference Series on Public Policy 39, 195-214.

Woodford, M., 2003. Interest and Prices. Princeton University Press.

Wicksell, K., 1898. Interest and Prices. London: Macmillan, 1936, translation of 1898 edition by Kahn, R.F..

Wicksell, K., 1906. Föreläsningar i nationalekonomi. Stockholm : Fritzes, vol. 2. English translation : Lectures on Political Economy, London : Routledge and Kegan Paul, 1934-1935, 2 vols.

Wicksell, K., 1907. The influence of the rate of interest on prices. The Economic Journal, 17, June, pp. 213-220.

Williams, J.C., 2003. The Natural Rate of Interest. The FRBSF Economic Letter, Number 2003-32. 


\section{A Assessment of alternative proxies for inflation expectations}

Alternative deflators can be considered for the computation of the real rate of interest from the nominal rate. The simplest one is the current annual increase in consumer prices (which is equivalent to the four-quarter moving average of quarterly price increases). The resulting real rate of interest, which can be qualified an ex post real rate, implies a very simple form for inflation expectations:

$$
E_{t}\left(\pi_{t+1}\right)=\frac{1}{4} \sum_{i=0}^{3} \pi_{t-i}
$$

To check for the acceptability of our model-consistent inflation expectations, we resort here to two alternative and more sophisticated ways of forming inflation expectations. A first method consists in deriving for each period $t$ the expectation of the next quarter inflation $\left(E_{t}\left(\pi_{t+1}\right)\right)$ from a univariate AR process estimated over the last 30 quarters $^{24}$. A second method which also allows to continuously update the forecasting model is the univariate time-varying coefficients procedure described by Stock and Watson (1996) and recently applied to the computation of real interest rates by Bekdache (1998) and Dotsey and Scholl (2003). Let us denote with $k$ the lag length, and with $\beta_{t}$ the $(k+1) \times 1$ vector of varying coefficients. Inflation is then assumed to follow

$$
\pi_{t}=\beta_{t}^{\prime}\left[\begin{array}{llll}
1 & \pi_{t-1} & \cdots & \pi_{t-k}
\end{array}\right]^{\prime}+\varepsilon_{t}
$$

and $\beta_{t}$ is a random walk

$$
\beta_{t}=\beta_{t-1}+\zeta_{t}
$$

The variance-covariance matrix of $\zeta_{t}$ is diagonal. The Kalman filter is then used to estimate the unobserved varying coefficients. The variances of $\zeta_{t}^{0}, \zeta_{t}^{1} \ldots, \zeta_{t}^{k}$, as well as the initial state vector $\beta_{0}$ and the lag length $k$ are chosen to minimize the conditional predictive squared errors $\sum\left(\pi_{t}-E_{t-1}\left(\pi_{t}\right)\right)^{2}$.

The root mean squared errors over the whole sample are 0.96 for the TVP method, 1.05 for the "moving AR" method, 1.07 for the four-quarter moving average and 0.96 for our model-consistent inflation expectations.

\section{B Filtering and smoothing}

A state-space model can be defined by the two following equations:

$$
\begin{aligned}
Y_{t} & =\mu_{t}+G_{t} \rho_{t}+M_{t} \varepsilon_{t} \\
\rho_{t} & =v_{t}+H_{t} \rho_{t-1}+N_{t} \xi_{t}
\end{aligned}
$$

\footnotetext{
${ }^{24}$ The AR lag length is chosen so as to minimize the predictive squared errors over the whole period: using only one lag proves to be sufficient. As regards the TVP method, we tried four values of $k$ (from one to four) and the longest lag is found to be the most efficient.
} 
where $Y_{t}$ is a $n$-vector of observed variables, $\rho_{t}$ is an unobserved state vector of dimension $p, \varepsilon_{t}$ and $\xi_{t}$ are independent gaussian white noises with zero mean and identity covariance matrices, $\mu_{t}, G_{t}, M_{t}, v_{t}, H_{t}, N_{t}$ are functions of an unknown vector of parameters $\theta$ and of the past values of $Y_{t} . \theta$ is finite dimensional and therefore, the model is parametric. Equation (16) is referred to as the measurement equation, and (17) as the transition equation. The Kalman filter and smoother provide a simple recursive way of recovering optimally the state vector.

Let denote with $\rho_{t \mid \tau}$ the estimate of $\rho_{t}$ upon information $Y^{\tau}=\left(Y_{1}, \ldots, Y_{\tau}\right)$, the output of the Kalman filter is $\rho_{t \mid t}$ and the output of the Kalman smoother is $\rho_{t \mid T}$, where $T$ is the number of observations. Let $\Sigma_{t \mid \tau}$ denote the covariance matrix of $\rho_{t}$ based upon information $Y^{\tau}$. The filtering procedure consists of the prediction and updating equations. The prediction equations are:

$$
\begin{aligned}
\rho_{t \mid t-1} & =v_{t}+H_{t} \rho_{t-1 \mid t-1} \\
\Sigma_{t \mid t-1} & =Q_{t-1}+H_{t} \Sigma_{t-1 \mid t-1} H_{t}^{\prime}
\end{aligned}
$$

and

$$
\begin{aligned}
Y_{t \mid t-1} & =\mu_{t}+G_{t} \rho_{t \mid t-1} \\
\Omega_{t \mid t-1} & =R_{t}+G_{t} \Sigma_{t \mid t-1} G_{t}^{\prime}
\end{aligned}
$$

where $R_{t}=M_{t} M_{t}^{\prime}, Q_{t}=N_{t} N_{t}^{\prime}, Y_{t \mid t-1}=E\left(Y_{t} \mid Y^{t-1}\right)$ and $\Omega_{t \mid t-1}=$ $\operatorname{Var}\left(Y_{t} \mid Y^{t-1}\right)$.

The updating equations are:

$$
\begin{aligned}
\rho_{t \mid t} & =\rho_{t \mid t-1}+K_{t}\left(Y_{t}-Y_{t \mid t-1}\right) \\
\Sigma_{t \mid t} & =\left(I d-K_{t} G_{t}\right) \Sigma_{t \mid t-1}
\end{aligned}
$$

where $K_{t}$, the gain of the filter, is given by:

$$
K_{t}=\Sigma_{t \mid t-1} G_{t}^{\prime}\left(R_{t}+G_{t} \Sigma_{t \mid t-1} G_{t}\right)^{-1}
$$

The filter consists in computing recursively these equations, given initial values $\rho_{0}$ and $\Sigma_{0}$. When $\rho_{t}$ follows a stationary process, we can take its unconditional mean and variance to initialize the filter. An alternative practice consists in replacing the initial value by the best guess of $\rho_{0}$, and $\Sigma_{0}$ then summarizes the confidence in the guess.

Let $\lambda_{t}$ denote the innovation in $Y_{t}$ (that is, $\lambda_{t}=Y_{t}-Y_{t \mid t-1}$ ), the loglikelihood can then be written as:

$$
L\left(Y^{T} ; \theta\right)=\frac{N T}{2} \log (2 \pi)-\frac{1}{2} \sum_{t=1}^{T}\left(\log \left|\Omega_{t \mid t-1}(\theta)\right|+\lambda_{t}^{\prime}(\theta) \Omega_{t-t-1}^{-1}(\theta) \lambda_{t}(\theta)\right)
$$

Whereas the filtering uses information up to time $t$ to estimate the unobserved state $\rho_{t}$, the smoothing uses information up to time $T$. The latter consists 
in computing backwards the following equations:

$$
\begin{aligned}
\rho_{t \mid T} & =\rho_{t \mid t}+F_{t+1}\left(\rho_{t+1 \mid T}-\rho_{t+1 \mid t}\right) \\
\Sigma_{t \mid T} & =\Sigma_{t \mid t}+F_{t+1}\left(\Sigma_{t+1 \mid T}-\Sigma_{t+1 \mid t}\right) F_{t+1}^{\prime}
\end{aligned}
$$

where $F_{t+1}=\Sigma_{t \mid t} H_{t+1}^{\prime} \Sigma_{t+1 \mid t}^{-1}$.

\section{Computation of the information matrix}

The main results presented here come from the article by Engle and Watson (1981). They use in particular the following expressions for derivatives of a symmetric matrix:

$$
\begin{aligned}
\frac{\partial|S|}{\partial x} & =|S| \operatorname{tr}\left(S^{-1} \frac{\partial S}{\partial x}\right) \\
\frac{\partial S^{-1}}{\partial x} & =-S^{-1} \frac{\partial S}{\partial x} S^{-1}
\end{aligned}
$$

And the considered estimate of the information matrix is:

$$
\hat{I}_{F i, j}=-\frac{1}{T} \sum_{t=1}^{T} E\left(\frac{\partial^{2} f_{t}\left(Y_{t} \mid Y^{t-1} ; \hat{\theta}_{T}\right)}{\partial \theta \partial \theta^{\prime}} \mid Y^{t-1}\right)
$$

Using (28) and (29), let differentiate (25):

$\frac{\partial L_{t}}{\partial \theta_{i}}=-\frac{1}{2} \operatorname{tr}\left(\Omega_{t \mid t-1}^{-1} \frac{\partial \Omega_{t \mid t-1}}{\partial \theta_{i}}\right)-\left(\frac{\partial \lambda_{t}}{\partial \theta_{i}}\right)^{\prime} \Omega_{t \mid t-1}^{-1} \lambda_{t}+\frac{1}{2} \lambda_{t}^{\prime} \Omega_{t \mid t-1}^{-1} \frac{\partial \Omega_{t \mid t-1}}{\partial \theta_{i}} \Omega_{t \mid t-1}^{-1} \lambda_{t}$

Taking the trace of the last term gives:

$$
\frac{\partial L_{t}}{\partial \theta_{i}}=-\frac{1}{2} \operatorname{tr}\left(\left(\Omega_{t \mid t-1}^{-1} \frac{\partial \Omega_{t \mid t-1}}{\partial \theta_{i}}\right)\left(I d-\Omega_{t \mid t-1}^{-1} \lambda_{t} \lambda_{t}^{\prime}\right)\right)-\left(\frac{\partial \lambda_{t}}{\partial \theta_{i}}\right)^{\prime} \Omega_{t \mid t-1}^{-1} \lambda_{t}
$$

that we write with obvious notations:

$$
\frac{\partial L_{t}}{\partial \theta_{i}}=L_{t}^{1}+L_{t}^{2}
$$

In order to get the second order derivative of the log-likelihood, we have to differentiate $L_{t}^{1}$ :

$$
\begin{aligned}
\frac{\partial L_{t}^{1}}{\partial \theta_{j}}= & -\frac{1}{2} \operatorname{tr}\left(\frac{\partial}{\partial \theta_{j}}\left(\Omega_{t \mid t-1}^{-1} \frac{\partial \Omega_{t \mid t-1}}{\partial \theta_{i}}\right)\left(I d-\Omega_{t \mid t-1}^{-1} \lambda_{t} \lambda_{t}^{\prime}\right)\right) \\
& -\frac{1}{2} \operatorname{tr}\left(\Omega_{t \mid t-1}^{-1} \frac{\partial \Omega_{t \mid t-1}}{\partial \theta_{i}} \Omega_{t \mid t-1}^{-1} \frac{\partial \Omega_{t \mid t-1}}{\partial \theta_{j}} \Omega_{t \mid t-1}^{-1} \lambda_{t} \lambda_{t}^{\prime}\right) \\
& +\frac{1}{2} \operatorname{tr}\left(\Omega_{t \mid t-1}^{-1} \frac{\partial \Omega_{t \mid t-1}}{\partial \theta_{i}} \Omega_{t \mid t-1}^{-1}\left(\frac{\partial \lambda_{t}}{\partial \theta_{j}} \lambda_{t}^{\prime}+\lambda_{t} \frac{\partial \lambda_{t}^{\prime}}{\partial \theta_{j}}\right)\right)
\end{aligned}
$$


Conditionally on $Y_{t}$, the only random terms of the latter equation are the $\lambda_{t}$, which are zero mean. The first term hence vanishes when taking the expected value of the equation. Moreover, recall that $\lambda_{t}=Y_{t}-\mu_{t}-G_{t} \rho_{t \mid t-1}$ and then that $\partial \lambda_{t} / \partial \theta_{i}$ only depends on the information at $t-1$, hence, the expected value of the third term is zero. All this leads to

$$
E\left(\frac{\partial L_{t}^{1}}{\partial \theta_{j}} \mid Y^{t-1}\right)=-\frac{1}{2} \operatorname{tr}\left(\Omega_{t \mid t-1}^{-1} \frac{\partial \Omega_{t \mid t-1}}{\partial \theta_{i}} \Omega_{t \mid t-1}^{-1} \frac{\partial \Omega_{t \mid t-1}}{\partial \theta_{j}}\right)
$$

Regarding $L_{t}^{2}$ :

$$
\frac{\partial L_{t}^{2}}{\partial \theta_{j}}=-\frac{\partial^{2} \lambda_{t}}{\partial \theta_{i} \partial \theta_{j}} \Omega_{t \mid t-1}^{-1} \eta_{t}-\left(\frac{\partial \lambda_{t}}{\partial \theta_{i}}\right)^{\prime} \frac{\partial \Omega_{t \mid t-1}^{-1}}{\partial \theta_{j}} \lambda_{t}-\left(\frac{\partial \lambda_{t}}{\partial \theta_{i}}\right)^{\prime} \Omega_{t \mid t-1}^{-1} \frac{\partial \lambda_{t}}{\partial \theta_{j}}
$$

For the same reasons as above, the first two terms vanishes when taking the conditional expected value. Since the third depends only on the past innovations, its conditional expected value is equal to itself:

$$
E\left(\frac{\partial L_{t}^{2}}{\partial \theta_{j}} \mid Y^{t-1}\right)=-\left(\frac{\partial \lambda_{t}}{\partial \theta_{i}}\right)^{\prime} \Omega_{t \mid t-1}^{-1} \frac{\partial \lambda_{t}}{\partial \theta_{j}}
$$

Finally, the ijth element of the information matrix is the negative of the sum of (35) and (37), that is:

$$
\hat{I}_{F i, j}=\sum_{t=1}^{T}\left[\left(\frac{\partial \lambda_{t}}{\partial \theta_{i}}\right)^{\prime} \Omega_{t \mid t-1}^{-1} \frac{\partial \lambda_{t}}{\partial \theta_{j}}+\frac{1}{2} \operatorname{tr}\left(\Omega_{t \mid t-1}^{-1} \frac{\partial \Omega_{t \mid t-1}}{\partial \theta_{i}} \Omega_{t \mid t-1}^{-1} \frac{\partial \Omega_{t \mid t-1}}{\partial \theta_{j}}\right)\right]
$$

\section{State-space form of our model}

In order to use the Kalman filter, equations (1)-(6) have to be written in the state-space form. (41) is the measurement equation and (42) is the corresponding transition equation.

$$
\begin{aligned}
& {\left[\begin{array}{c}
\Delta y_{t} \\
\pi_{t}
\end{array}\right]=G\left[\begin{array}{c}
a_{t} \\
a_{t-1} \\
z_{t} \\
z_{t-1}
\end{array}\right]+\left[\begin{array}{ccc}
0 & 0 & 0 \\
\alpha_{1} & \alpha_{2} & \alpha_{3}
\end{array}\right]\left[\begin{array}{c}
\pi_{t-1} \\
\pi_{t-2} \\
\pi_{t-3}
\end{array}\right]+\left[\begin{array}{c}
\varepsilon_{t}^{y} \\
\varepsilon_{t}^{\pi}
\end{array}\right]} \\
& {\left[\begin{array}{c}
a_{t} \\
a_{t-1} \\
z_{t} \\
z_{t-1}
\end{array}\right]=H\left[\begin{array}{c}
i_{t-1} \\
a_{t-2} \\
z_{t-1} \\
z_{t-2}
\end{array}\right]+\Omega\left[\begin{array}{c}
i_{t-2} \\
\pi_{t-1} \\
\pi_{t-2} \\
\pi_{t-3} \\
\pi_{t-4}
\end{array}\right]+\left[\begin{array}{c}
\varepsilon_{t} \\
0 \\
\varepsilon_{t}^{z} \\
0
\end{array}\right]}
\end{aligned}
$$




$$
\begin{aligned}
& \text { with } G=\left[\begin{array}{cccc}
\theta_{y} & 0 & 1 & -1 \\
0 & 0 & 0 & \beta
\end{array}\right], H=\left[\begin{array}{cccc}
1 & 0 & 0 & 0 \\
1 & 0 & 0 & 0 \\
-\lambda \theta_{r} & -\lambda \theta_{r} & \Phi_{1}-\beta \lambda & \Phi_{2}-\beta \lambda \\
0 & 0 & 1 & 0
\end{array}\right] \\
& \text { and } \Omega=\left[\begin{array}{cccccc}
0 & 0 & 0 & 0 & 0 & 0 \\
0 & 0 & 0 & 0 & 0 & 0 \\
\lambda & \lambda & -\lambda \alpha_{1} & -\lambda\left(\alpha_{2}+\alpha_{1}\right) & -\lambda\left(\alpha_{3}+\alpha_{2}\right) & -\lambda \alpha_{3} \\
0 & 0 & 0 & 0 & 0 & 0
\end{array}\right] \text {. }
\end{aligned}
$$




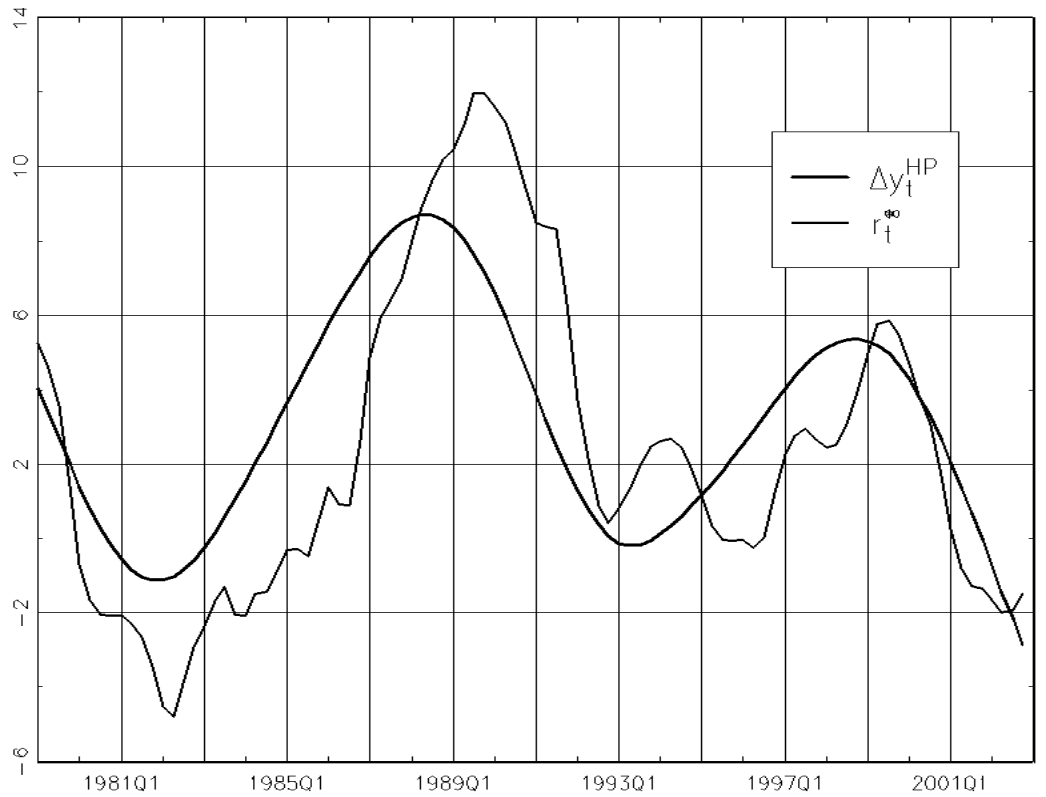

Figure 1: HP-filtered output growth \& estimate of the natural rate of interest when the ratio $\theta_{r} / \theta_{y}$ is not constrained (the HP-filtered output growth series is demeaned and rescaled).

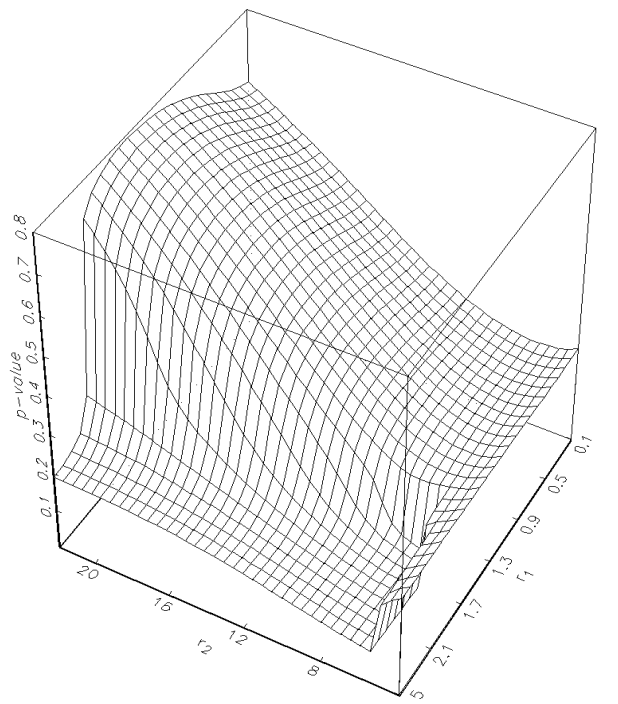

Figure 2: Lagrange Multiplier test ( $p$-values). 


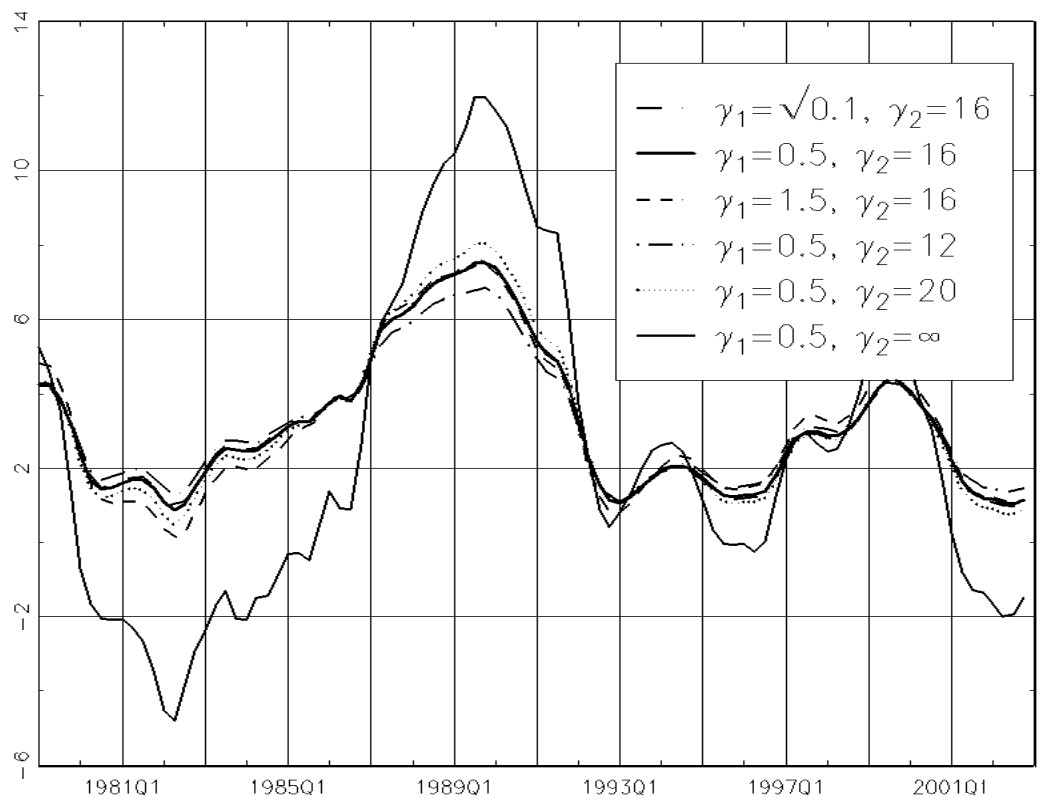

Figure 3: Natural rate of interest: influence of $\gamma_{1}$ and $\gamma_{2}$.

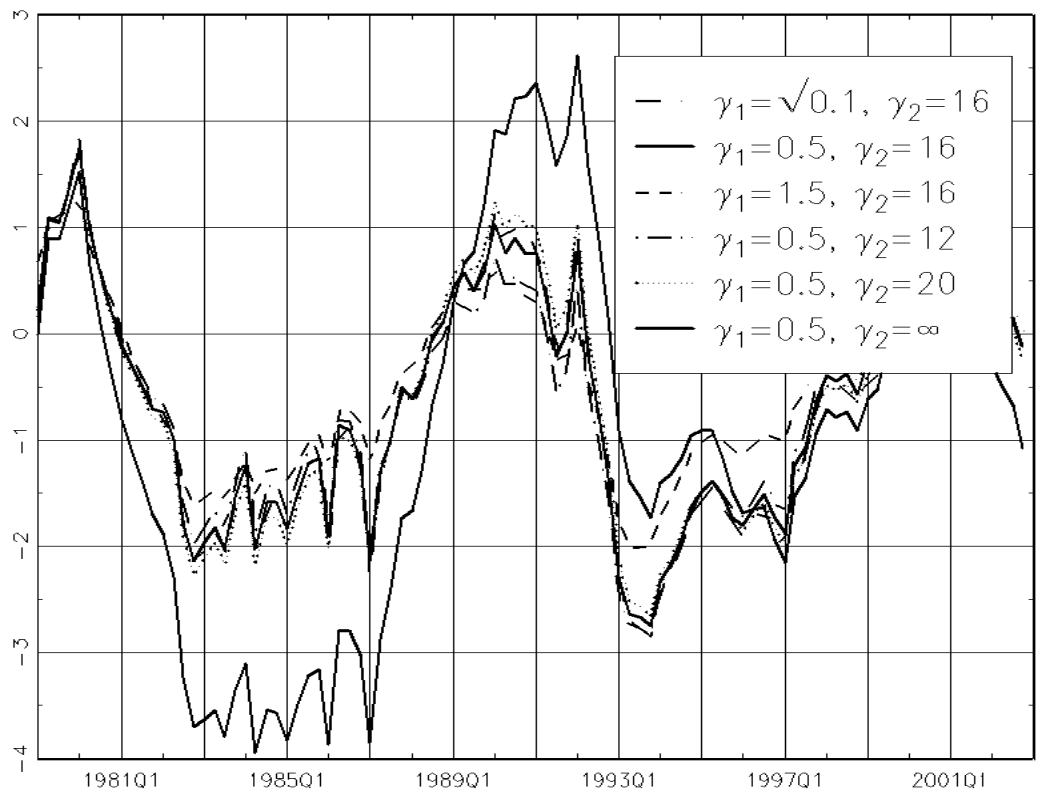

Figure 4: Output gap: influence of $\gamma_{1}$ and $\gamma_{2}$. 


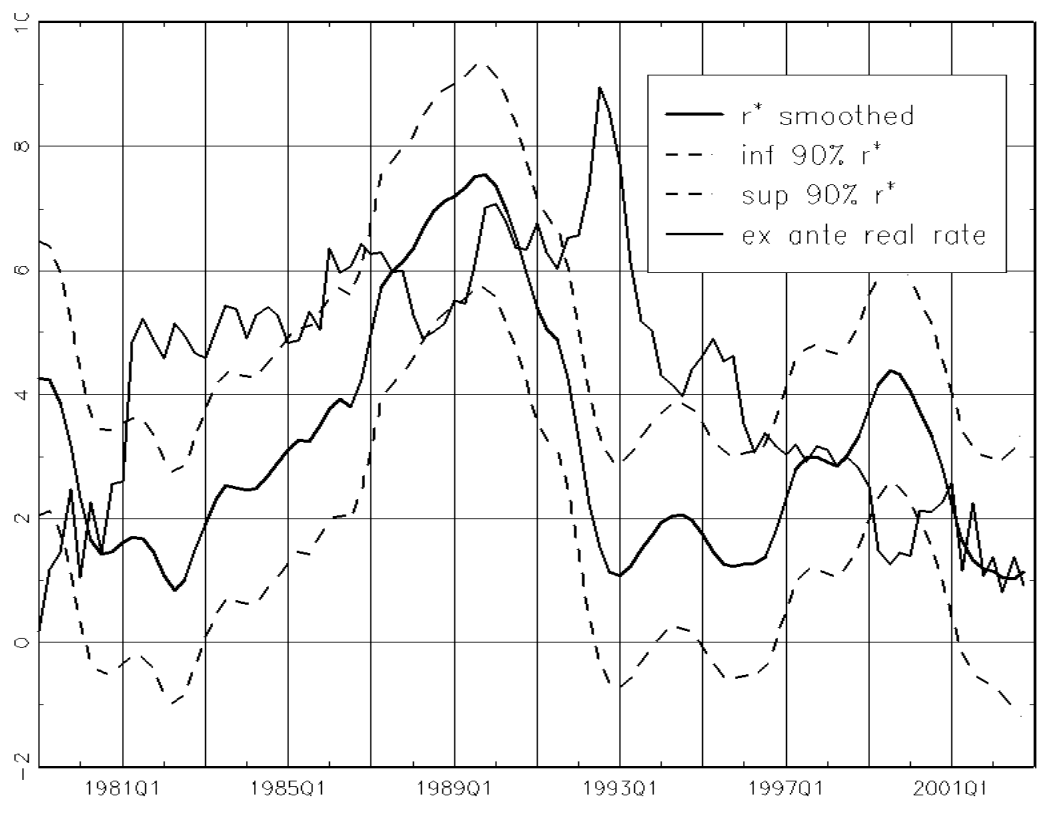

Figure 5: Natural rate of interest $\left(\gamma_{1}=0.5, \gamma_{2}=16\right)$.

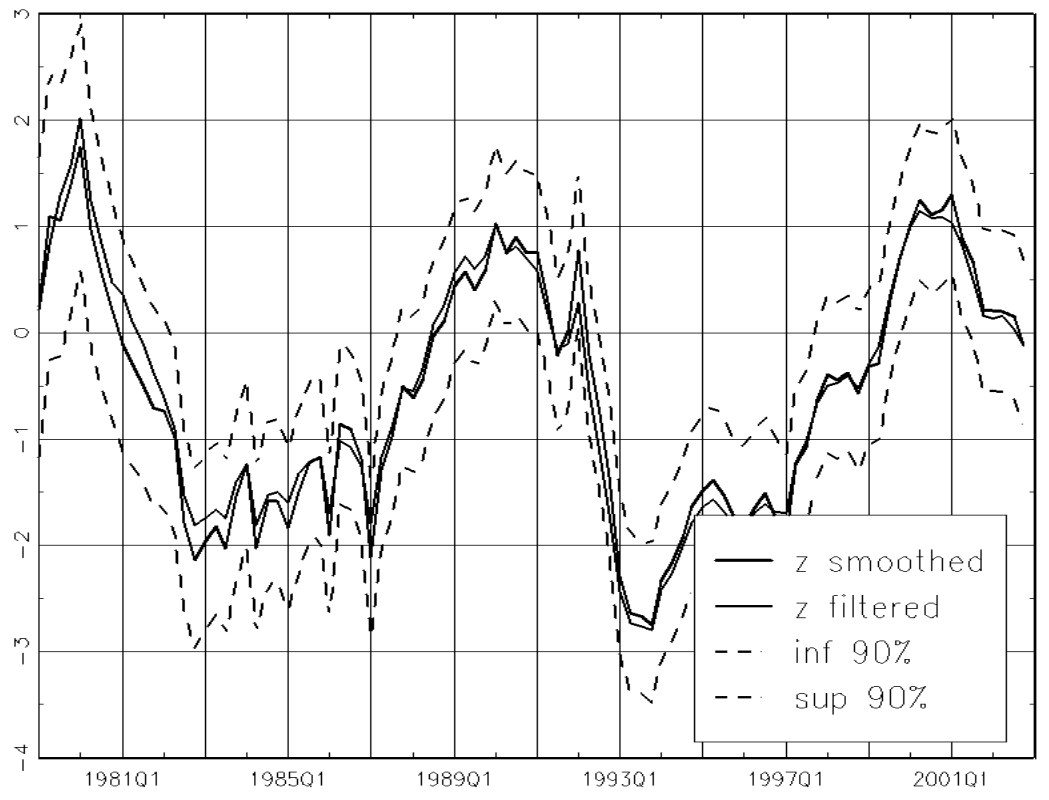

Figure 6: Output gap $\left(\gamma_{1}=0.5, \gamma_{2}=16\right)$. 


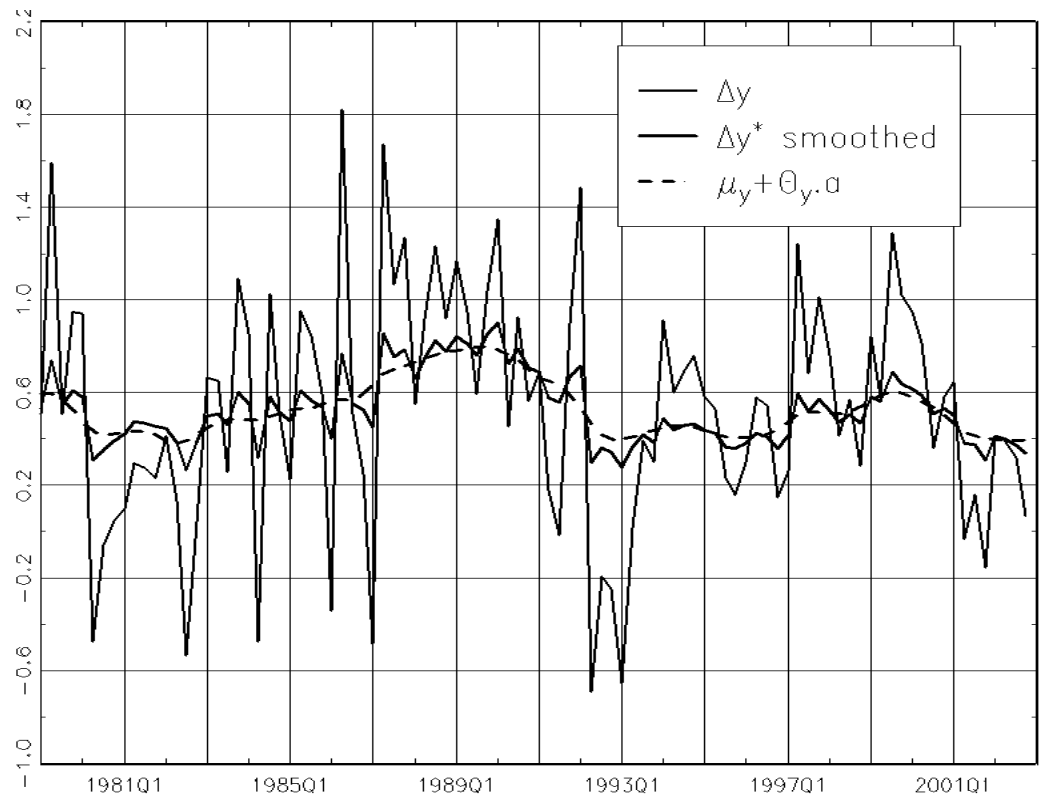

Figure 7: Potential output growth $\left(\gamma_{1}=0.5, \gamma_{2}=16\right)$.

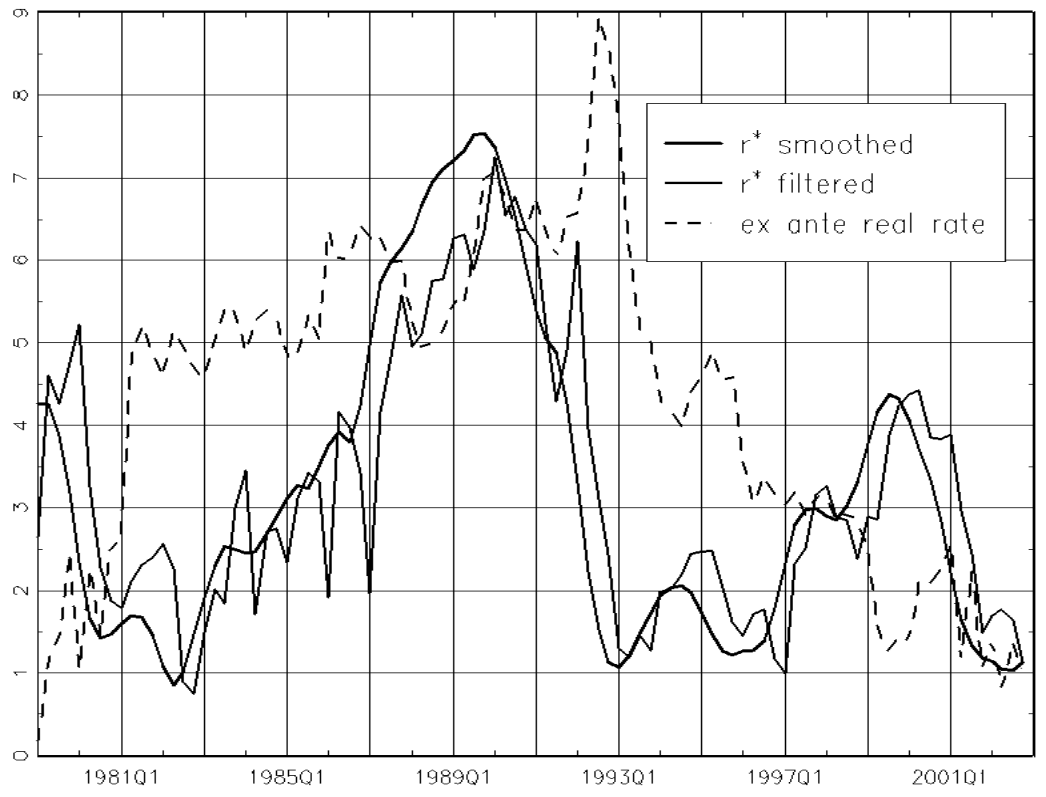

Figure 8: Filtered (one-sided) and smoothed (two-sided) natural rate of interest. 


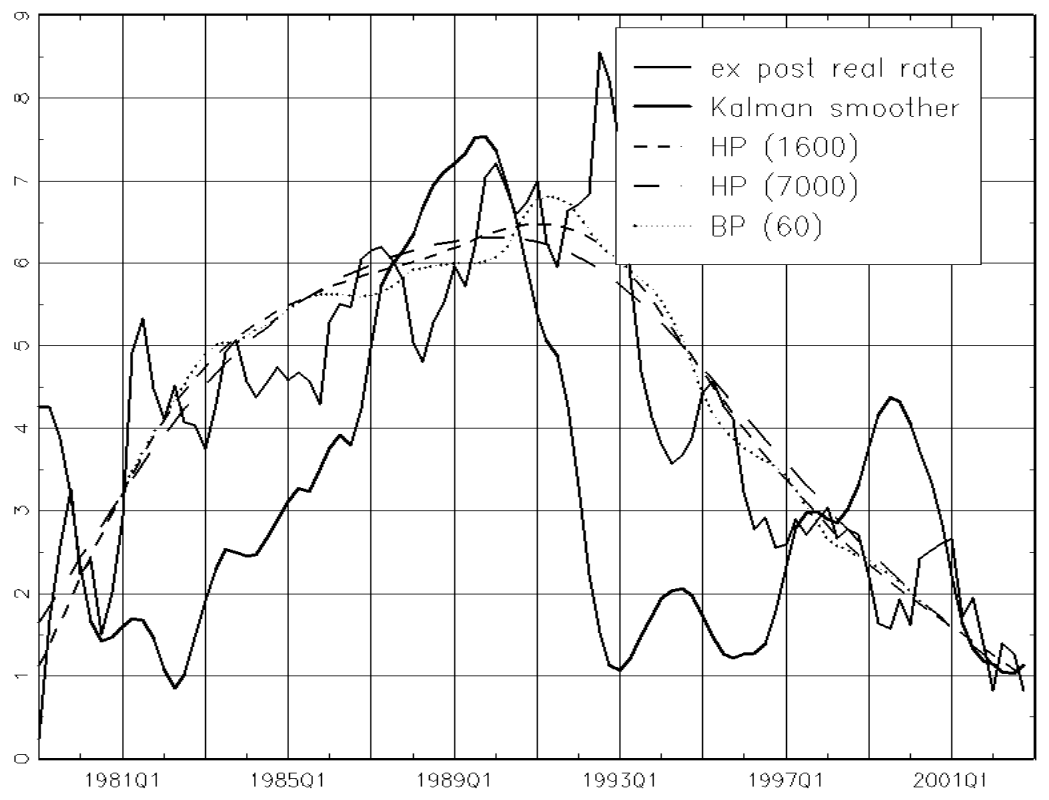

Figure 9: Equilibrium real rate estimates yielded by various filters.

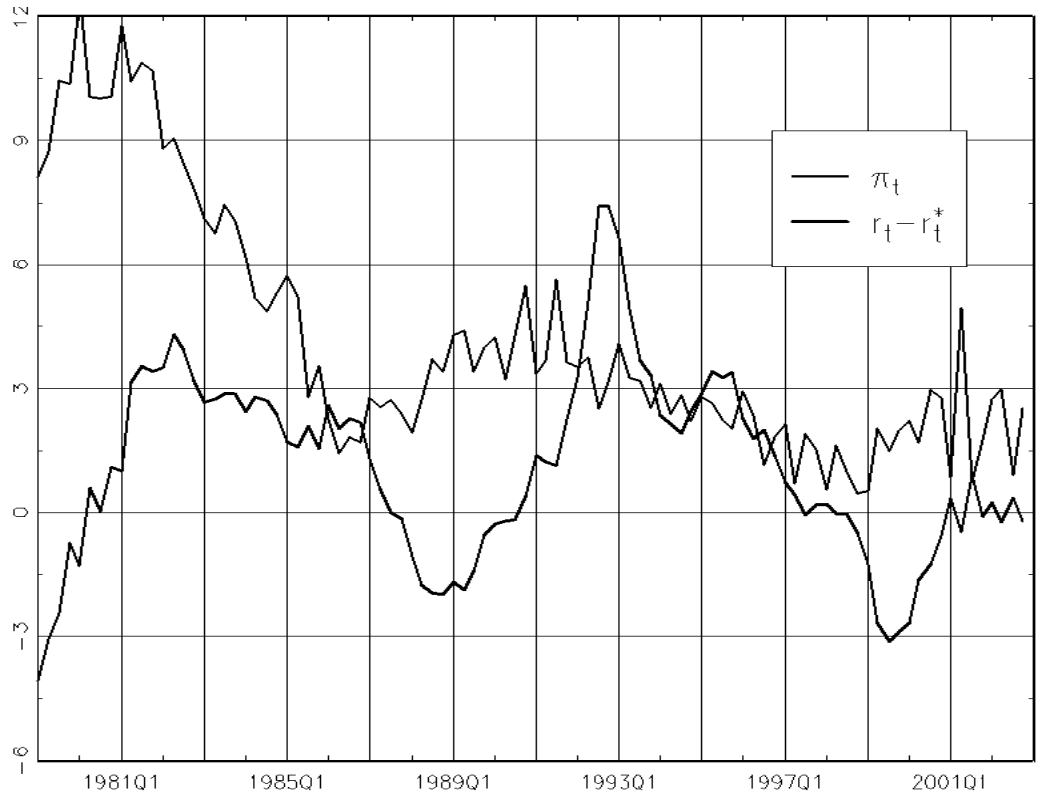

Figure 10: Inflation and estimated real rate gap. 


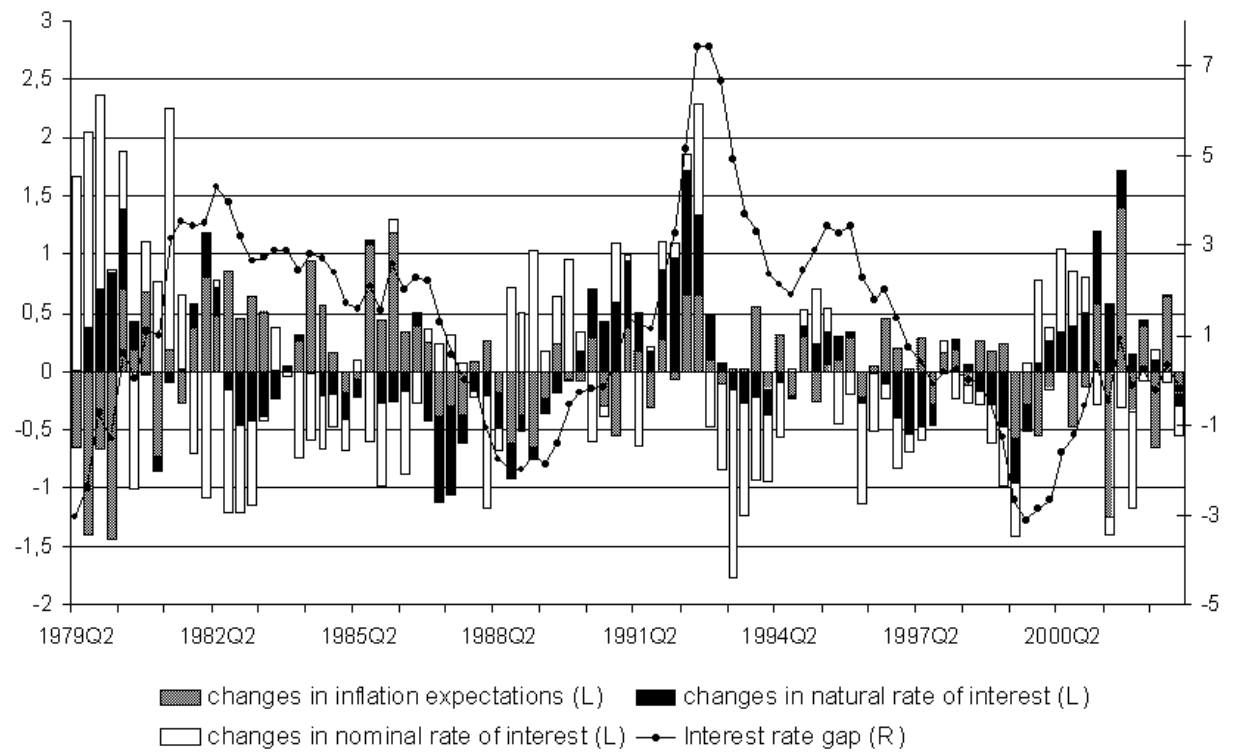

Figure 11: Breakdown of the interest rate gap.

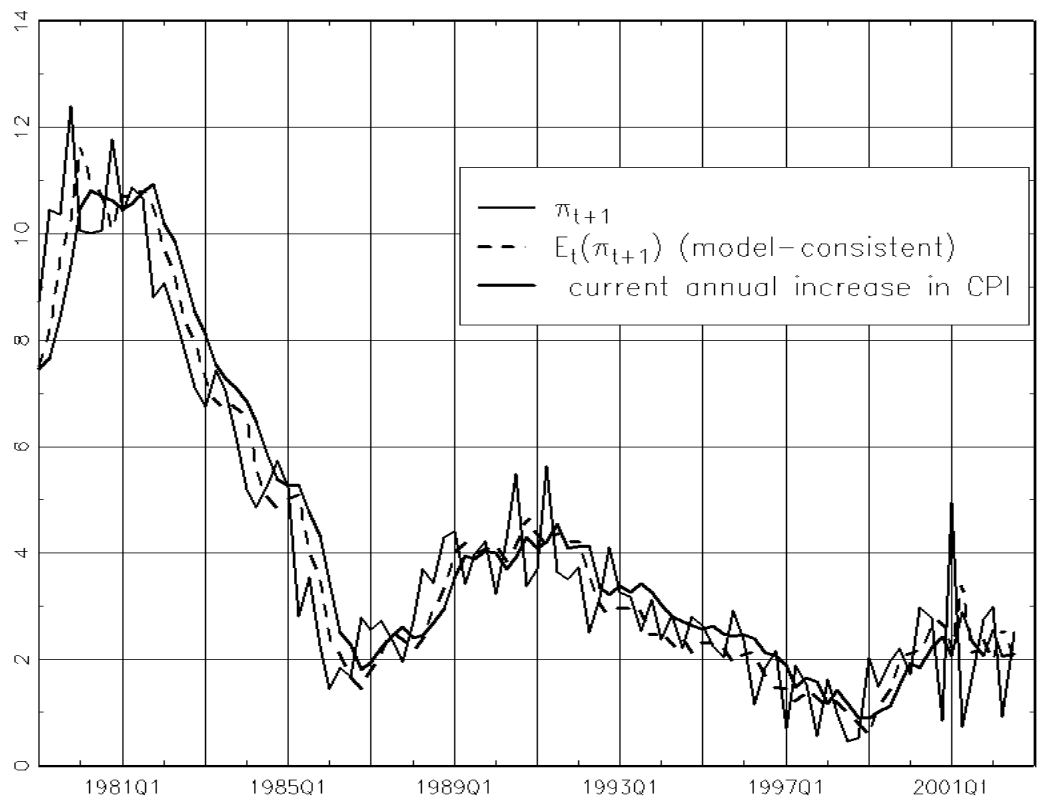

Figure 12: Inflation, model-consistent inflation expectations and current annual increase in consumer prices. 


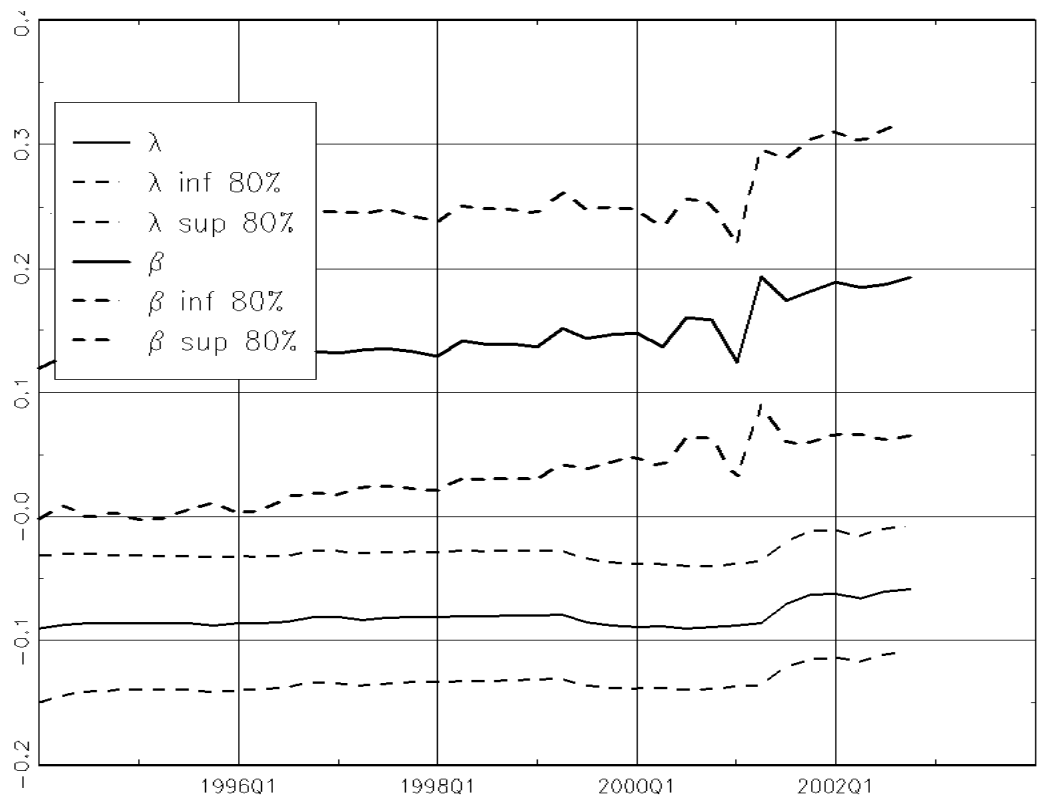

Figure 13: Recursive estimates of monetary policy transmission parameters $\lambda$ and $\beta$. 